\title{
C-fos Expression in the Pons and Medulla of the Cat during Carbachol-induced Active Sleep
}

\author{
J. Yamuy, J. R. Mancillas, F. R. Morales, and M. H. Chase \\ Department of Physiology, Department of Anatomy and Cell Biology, and the Brain Research Institute, University of \\ California, Los Angeles, California 90024
}

\begin{abstract}
Microinjection of carbachol into the rostral pontine tegmentum of the cat induces a state that is comparable to naturally occurring active (REM, rapid eye movement) sleep. We sought to determine, during this pharmacologically induced behavioral state, which we refer to as active sleep-carbachol, the distribution of activated neurons within the pons and medulla using c-fos immunocytochemistry as a functional marker.

Compared with control cats, which were injected with saline, active sleep-carbachol cats exhibited higher numbers of c-fos-expressing neurons in (1) the medial and portions of the lateral reticular formation of the pons and medulla, (2) nuclei in the dorsolateral rostral pons, (3) various raphe nuclei, including the dorsal, central superior, magnus, pallidus, and obscurus, (4) the medial and lateral vestibular, prepositus hypoglossi, and intercalatus nuclei, and (5) the abducens nuclei. On the other hand, the mean number of c-fosexpressing neurons found in the masseter, facial, and hypoglossal nuclei was lower in carbachol-injected than in control cats.
\end{abstract}

The data indicate that c-fos expression can be employed as a marker of state-dependent neuronal activity. The specific sites in which there were greater numbers of c-fosexpressing neurons during active sleep-carbachol are discussed in relation to the state of active sleep, as well as the functional role that these sites play in generating the various physiological patterns of activity that occur during this state.

[Key words: active sleep, atonia, carbachol, c-fos expression, Fos protein, immunocytochemistry]

Active sleep is a state present in mammals characterized polygraphically by a desynchronized EEG activity, muscular atonia, high-amplitude bioelectrical waves in the pons, lateral geniculate nuclei, and occipital cortex called ponto-geniculo-occipital (PGO) waves, and rapid eye movements (for recent reviews, see Siegel, 1989; Steriade and McCarley, 1990; Jones, 1991). A great deal of fundamental information has been obtained regarding the physiology, pharmacology, and anatomical location of neuronal populations implicated in active sleep (which is also called paradoxical, REM, and desynchronized sleep; Siegel, 1989; Steriade and McCarley, 1990; Jones, 1991). For example, it has

\footnotetext{
Received June 19, 1992; revised Nov. 27, 1992; accepted Dec. 3, 1992.

We are grateful to Mrs. Sharon Sampogna for her excellent histological work and Robert Tran for his technical assistance. We thank Dr. Dennis Slamon for his generous contribution of the antibody to Fos. This work was supported by U.S. Public Health Service Grants AGO4307, NS09999, and MH43362.

Correspondence should be addressed to Jack Yamuy, Department of Physiology, UCLA School of Medicine, Los Angeles, CA 90024.

Copyright (C) 1993 Society for Neuroscience $0270-6474 / 93 / 132703-16 \$ 05.00 / 0$
}

been shown that a state comparable to active sleep can be elicited by the microinjection of cholinergic agonists, such as carbachol, into the rostral pontine tegmentum of chronic cats. The evoked state resembles active sleep by behavioral, polygraphic, and electrophysiologic criteria (George et al., 1964; Baghdoyan et al., 1987, 1989; Morales et al., 1987); it can also be reliably and repeatedly induced. Thus, it offers significant methodological advantages in terms of an experimental paradigm to study the state-dependent activity of CNS neurons.

Furthermore, at a cellular level of analysis, several lines of evidence indicate that neurons that are located in certain structures of the rostral pontine tegmentum and in the medullary reticular formation are involved in the generation and maintenance of active sleep (Siegel, 1989; Steriade and McCarley, 1990; Jones, 1991). Nonetheless, the specific sets of neurons within the pons and medulla that are responsible for this behavioral state have not been clearly demarcated. A major difficulty has been in relating the activity of identified population of neurons to the behavioral state of the animal and to specific physiological processes; this problem reflects, in part, the limitations of the methodologies that have been employed. For example, with electrophysiological recording techniques, only a fraction of the neuronal populations in a given area can be sampled. On the other hand, whereas a large number of cells can be examined employing classical anatomical and neurochemical procedures, the data lack the necessary functional correlates. Problems such as these indicate the need to incorporate new techniques that can assess, during active sleep, the functional state of large populations of anatomically identified neurons.

Recently, the expression of the proto-oncogene c-fos has been related to certain forms of neuronal activation (Hunt et al., 1987; Sagar et al., 1988; Menétrey et al., 1989; for review, see Morgan and Curran, 1991). The expression of this gene can be detected with single-cell resolution by the nuclear localization of its protein product (Fos) using immunocytochemical techniques (Hunt et al., 1987). However, there are a number of factors that must be taken into account when dealing with an analysis of the in vivo expression of $\mathrm{c}$-fos. A carefully designed experimental protocol and strict control experiments are required in order to optimize and set a baseline of c-fos expression. In addition, there are potential problems in interpreting the results of such studies (see Dragunow and Faull, 1989). Nevertheless, by taking the preceding into account, we believe that it is possible to obtain an anatomical correlate of neuronal activation that occurs during a behavioral state by mapping the cellular expression of c-fos.

In the present study, we tested the hypothesis that the neu- 
ronal populations activated during the carbachol-induced state, which has been used as a model of naturally occurring active sleep, can be detected using c-fos immunocytochemistry. Our results show that in carbachol-injected cats, ncurons located in pontine and medullary regions that have been previously implicated in active sleep exhibit c-fos immunoreactivity. In addition, it was observed that other regions contained c-fos-expressing neurons, which suggests that they are involved in mediating the various patterns of physiological activity that are present during this state.

Preliminary results of this work have been previously reported Yamuy et al., 1991).

\section{Materials and Methods}

\section{Experiments were performed on five adult cats.}

Surgical procedures. The following surgical procedures were performed under sodium pentobarbital anesthesia $(40 \mathrm{mg} / \mathrm{kg}$, i.p.). The head of the cat was positioned in a heavy-duty stereotaxic frame and the calvarium was exposed. Stainless steel screws were threaded into the calvarium overlying the frontal and parietal lobes in order to record the EEG. Another pair of screws were threaded into the orbital portion of the frontal bone to monitor electro-oculographic (EOG) activity. Bipolar strut electrodes were implanted bilaterally into the lateral geniculate nuclei [A 5.5, L 9, H 5, according to Berman's (1968) coordinates]; these electrodes were used to monitor ponto-geniculo-occipital (PGO) waves. A Winchester plug, connected to these electrodes, and a chronic head-restraining device were bonded to the calvarium with acrylic cement. A hole 4-5 $\mathrm{mm}$ in diameter was drilled in the calvarium overlying the cerebellar cortex and covered with a bonewax plug. This hole provided access to a cannula for drug microinjection. At the end of surgery, antibiotics were administered parenterally and topically. Details of the surgical preparation of cats for the chronic monitoring of behavioral states have been previously reported (Morales et al., 1981).

Postsurgical procedures. Following surgery, incision margins were kept clean and topical antibiotics were administered on a daily basis. Following a 5-7 d period, the cats were adapted to the recording apparatus; thereafter, they exhibited spontaneous periods of wakefulness, quiet sleep, and active sleep.

Experimental paradigm. Following the adaptation period, the dura mater underlying the access hole was cut, under halothane anesthesia, to provide for the descent of an injection cannula. Approximately 36 $\mathrm{hr}$ later, the cats were placed in the recording apparatus. Two stainless steel wires, insulated except for $1 \mathrm{~mm}$ at their tips, were inserted into the cervical muscles to monitor their electromyographic activity.

The EEG, EMG, EOG, and PGO waves were recorded on a Grass polygraph (model 6 ). The data were stored on magnetic tape for off-line analysis using a Vetter instrumentation tape recorder (model D). Following a baseline recording period of $1 \mathrm{hr}$, the cannula of a $2 \mu \mathrm{l}$ Hamilton syringe was lowered through the access hole to $\mathrm{P} 2.0, \mathrm{~L} 1.3, \mathrm{H}-5.5$ (Berman, 1968) at an inclination of $36^{\circ}$ in order to avoid the tentorium cerebelli. Two cats were injected with saline $(0.25 \mu \mathrm{l})$ and three cats were injected with a solution of carbachol ( $4 \mu \mathrm{g}$ in $0.25 \mu \mathrm{l}$ of saline). The injection periods lasted $1 \mathrm{~min}$ and the cannula was kept in place during the following $10 \mathrm{~min}$. Recording periods lasted approximately $2 \mathrm{hr}$ from the beginning of the injection. This period of time was chosen because the $c$-fos protein product reaches a high concentration $2 \mathrm{hr}$ after adequate stimulation (Dragunow and Faull, 1989). At the end of the experiment, the site of injection was marked with $0.25 \mu \mathrm{l}$ of Chicago sky blue and the animal was killed with an overdose of sodium pentobarbital $(50 \mathrm{mg} / \mathrm{kg}$, i.p.).

Perfusion and fxation. The cats were perfused with 3 liters of saline followed by 3 liters of a solution of $10 \%$ formaldehyde in saline. The brainstem was dissected and submerged in Bouin's solution for $8 \mathrm{hr}$. The tissue was then repeatedly rinsed in $80 \%$ alcohol over a $4 \mathrm{~d}$ period.

Immunocytochemistry. After dehydration through an alcohol series, the tissue was cleared in xylene and embedded in "Paraplast Plus" paraffin embedding media. Brainstem sections $(7 \mu \mathrm{m})$ were cut with an AO rotary microtome, mounted on SuperFrost Plus slides, and dried overnight in a $37^{\circ} \mathrm{C}$ oven. The slides were deparaffinized, rehydrated through descending grades of alcohol, and placed in Tris buffer $(\mathrm{pH}$ 7.5). Nonspecific binding sites were saturated by incubation for $1 \mathrm{hr}$ in "Zellers" blocking solution in the case of sections immunostained by the alkaline phosphatase method, and in $2 \%$ normal goat serum (NGS) with $0.3 \%$ Triton $\mathrm{X}$ in Tris-buffered saline (TBS; $\mathrm{pH} \mathrm{7.4)}$ in the case of sections that were immunostained using the avidin-biotin procedure (Hsu et al., 1981). In all cases, sections were incubated overnight in a rabbit polyclonal Fos antiserum raised against an in vitro-translated gene product. Incubations were carried out overnight at room temperature in a humified chamber in a primary antibody dilution of $1: 10,000$. Control slides were similarly incubated in a blocking or NGS solution.

Fos immunoreactivity was visualized by the alkaline phosphatase method using an anti-rabbit alkaline phosphatase-conjugated secondary antibody (Promega Corp., Madison, WI) and by the avidin-biotin procedure using the anti-rabbit ABC "Elite" kit (Vector Laboratories, Burlingame, CA). In the former case, slides were rinsed in TBST (Tris-

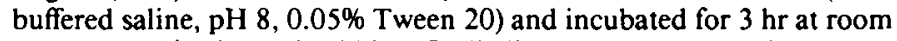
temperature in the anti-rabbit IgG alkaline phosphatase conjugate at a dilution of 1:1000. After rinsing in TBST, they were reacted with Promega NTB $(6.6 \mu \mathrm{l} / \mathrm{ml})$-BCIP $(3.3 \mu \mathrm{l} / \mathrm{ml})$ in TBS (pH 9.5) for $30-60 \mathrm{~min}$. The reaction was stopped by repeated rinsing with EDTA/TBS $(\mathrm{pH} 8)$ for $45-60 \mathrm{~min}$. During this step the slides were kept in a darkened environment. After processing, a coverslip was added using $2: 1$ glycerinEDTA/Tris buffer and the slides were examined under bright-field illumination. For immunoperoxidase staining, a second set of slides was rinsed four times for $20 \mathrm{~min}$ in TBS and incubated in biotinylated antirabbit IgG diluted 1:2000 in TBS. After rinsing in TBS, they were incubated for $1 \mathrm{hr}$ in avidin-biotinylated horseradish peroxidase complex at a 1:100 dilution in TBS. The slides were then rinsed in TBS and peroxidase activity was visualized using equal parts $0.02 \%$ hydrogen peroxidase and $0.1 \%$ diaminobenzidine tetrahydrochloride (Sigma) in TBS ( $\mathrm{pH} \mathrm{7.6)}$ for 8-15 min. After a final three rinses (15 min each) in TBS, the slides were rinsed in running water for $5 \mathrm{~min}$ followed by a distilled water rinse. They were counterstained in cresyl violet (Chroma), dehydrated, and cleared in xylene.

Data analysis. In the present study, brainstem sections at the level of the caudal portion of the trigeminal mesencephatic nucleus (MesV) and at masseter (nV), abducens (nVI), facial (nVII), and hypoglossal (nXII) motor nuclei were selected for analysis because they comprise areas of the brainstem that have been implicated in the mechanisms of generation of active sleep phenomena (for review, see Vertes, 1984; Siegel, 1989; Jones, 1991). Photomicrographs were taken using a Nikon Microphot FXA microscope under conventional and Nomarski optics. Cell counts of Fos immunoreactivity were performed by bright-field $\mathrm{mi}$ croscopy using a Leitz (ortholux) microscope. Using a camera lucida attachment, the distribution of labeled neurons was drawn from four superimposed, adjacent sections that had been processed simultaneously from control and carbachol-injected cats. Immunoreactive cells in each animal were counted in the structures described below (see Results and Tables 1,2 ). Because the activity in a number of pontomedullary structures is known to be correlated during active sleep, a multivariate method for comparing mean profiles between groups, such as a multivariate ANOVA (MANOVA) test, is necessary. However, a MANOVA comparison of mean profiles requires, at a minimum, more observations than structures (Afifi and Azen, 1979). In this study, we investigated a total of 51 pontomedullary structures in five animals. Therefore, we are limited to reporting the mean number of cells from all structures investigated combined into a single summary measure (as a betweengroup repeated-measure ANOVA test does) and descriptive statistics for structure-by-structure comparisons since we do not have enough information to control the structure-by-structure type I (false positive) error rates.

\section{Results}

\section{Polygraphic recordings}

The behavior of the saline-injected cats differed from that exhibited by the cats that received carbachol. In Figure 1, $A$ and $B$ consist of polygraphic records from a representative control cat that remained awake before (Fig. $1 A$ ) and following (Fig. $1 B$ ) saline microinjection. Control animals were aroused by light tactile stimulation whenever a pattern of EEG synchronization appeared in the polygraphic record. The cats that reccived carbachol were awake before the drug was injected (Fig. 1C). Following carbachol microinjection (Fig. 1D), the animals exhibited desynchronization of the EEG, PGO waves, rapid eye movements, and atonia. We will refer to this carbachol-induced 
A. Pre-Saline

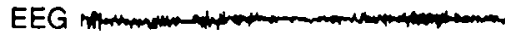

LON

EOG

EMG

\section{Pre-Carbachol}

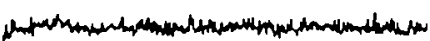

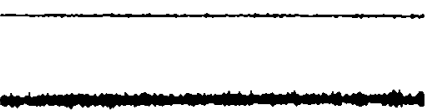

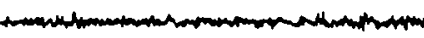

B. Saline

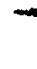

Antons

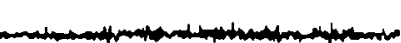

D. Carbachol

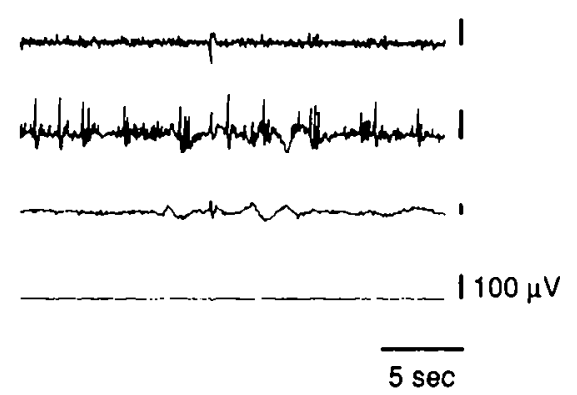

Figure 1. Polygraphic recordings from a control $(A$ and $B)$ and an active sleepcarbachol $(C$ and $D)$ cat. The control animal is awake before $(A)$ and after $(B)$ saline is injected into the pontine tegmentum. Whereas prior to carbachol administration the experimental cat is the animal shows the polygraphic signs of active sleep, such as a desynchronized EEG, PGO waves recorded in the lateral geniculate nucleus, rapid eye movements, and a complete atonia $(D)$. Calibration: $5 \mathrm{sec}, 100 \mu \mathrm{V}$. awake $(C)$, following the drug injection
A
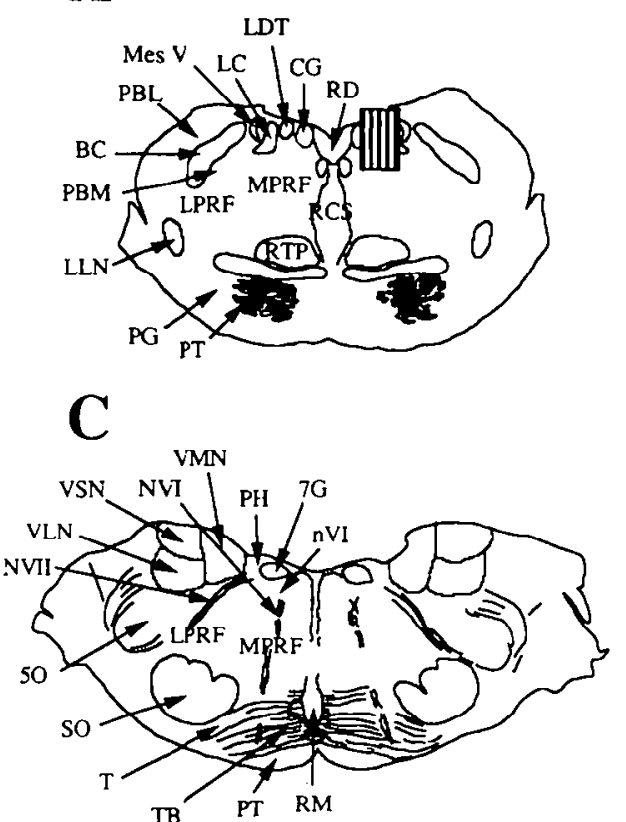

B

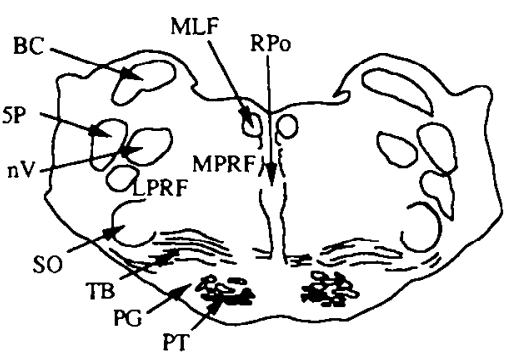

D

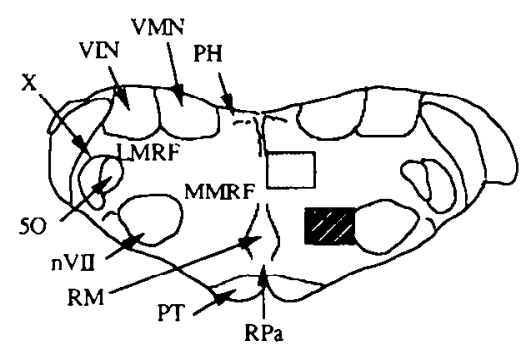

Figure 2. Frontal pontine $(A-C)$ and medullary ( $D$ and $E$ ) schematics from a representative cat that illustrate most of the structures that were investigated in the present study. The sections were taken from brainstem levels passing through the mesencephalic trigeminal nucleus (Mes $V$ in $A$ ) and the masseter ( $n V$ in $B$ ), abducens ( $n V I$ in $C$ ), facial ( $n V I I$ in $D$ ), and hypoglossal $(n X I I$ in $E$ ) motor nuclei. The rectangles in $A$ and $D$ indicate the areas where the photomicrographs of Figures 7-9 were taken. $5 I$, nucleus tractus spinalis trigemini interpolaris; $5 O$, nucleus tractus spinalis trigemini oralis; $5 P$, nucleus nervi sensibilis trigemini principalis; $7 G$, genu of the facial nerve; $B C$, brachium conjunctivum; $C u n$, cuneatus nucleus; $I n t$, nucleus intercalatus; $I O$, inferior olive; $L L N$, lateral lemniscus nucleus; $M L F$, fasciculus longitudinalis medialis; $N V I$, abducens nerve; $N V I I$, facial nerve; $N X I I$, hypoglossal nerve; $P G$, pontine gray; $P T$, pyramidal tract; $R C S$, raphe centralis superior; $R T P$, nucleus reticularis tegmenti pontis; $S O$, superior olive; $T$, nucleus of the trapezoid body; $T B$, trapezoid body; VIN, inferior vestibular nucleus; $V L N$, lateral vestibular nucleus; VSN, superior vestibular nucleus; $X$, nucleus $X$. Other abbreviations are defined in the text. 
Table 1. Mean number of Fos + neurons in the RF of the pons and medulla during wakefulness and AS-carbachol

\begin{tabular}{|c|c|c|}
\hline & Wakefulness & AS-carbachol \\
\hline Structure & Mean $\pm \operatorname{SEM}(N)$ & Mean $\pm \operatorname{SEM}(N)$ \\
\hline \multicolumn{3}{|l|}{ Lateral RF } \\
\hline \multicolumn{3}{|l|}{ Pons } \\
\hline $\mathbf{P}-2.5$ & $62 \pm 24.5(2)$ & $138 \pm 20$ \\
\hline$P-4.5^{*}$ & $51 \pm 12.5(2)$ & $106 \pm 10.7(3)$ \\
\hline$P-6$ & $5 \pm 3.5$ & $29 \pm 16.2(3)$ \\
\hline \multicolumn{3}{|l|}{ Medulla } \\
\hline$P-8$ & $8 \pm 1.0$ & $26 \pm 16.0(3)$ \\
\hline$P-12.5$ & $41 \pm 2.0$ & $67 \pm 14.7(3)$ \\
\hline \multicolumn{3}{|l|}{ Medial RF } \\
\hline \multicolumn{3}{|l|}{ Pons } \\
\hline $\mathrm{P}-2.5^{*}$ & $95 \pm 12.5(2)$ & $415 \pm 27$ \\
\hline$P-4.5^{*}$ & $37 \pm 13.5(2)$ & $305 \pm 60.8(3)$ \\
\hline$P-6$ (dorsal)* & $7 \pm 4.0$ & $47 \pm 1.7$ \\
\hline$P-6$ (ventral)* & $7 \pm 4.5$ & $68 \pm 11.4(3)$ \\
\hline \multicolumn{3}{|l|}{ Medulla } \\
\hline$P-8$ (dorsal)* & $5 \pm 2.0$ & $44 \pm 8.2$ \\
\hline$P-8$ (ventral)* & $28 \pm 12.5(2)$ & $197 \pm 35.2(3)$ \\
\hline Nucleus reticularis lateralis* & $24 \pm 10.5(2)$ & $72 \pm 9.0$ \\
\hline Nucleus reticularis paramedianus* & $1 \pm 0.5$ & $43 \pm 4.7$ \\
\hline
\end{tabular}

Values are means \pm SEM. Stereotaxic coordinates are according to Berman (1968).

${ }^{*} p<0.05$ according to Student's $t$ test. Further statistical details are given in the Results.

state as active sleep-carbachol (AS-carbachol). The latency to the onset of AS-carbachol was $3 \mathrm{~min}$ (two cats) and $10 \mathrm{~min}$ (one cat). The AS-carbachol state lasted throughout the experimental period; only transiently did the cats exhibit periods of wakefulness, which were elicited by noise in the environment. These periods of wakefulness were signaled by the presence of cervical muscle tone and occasionally by body movements. The mean duration of AS-carbachol was $111 \pm 16 \mathrm{~min}( \pm \mathrm{SD})$ and the mean percentage time spent in this state was $98.4 \%$.

\section{Characteristics of c-fos immunoreactivity}

Fos immunoreactivity was restricted to the nuclei of cells. There were variations in the intensity of nuclear immunostaining of different neurons within an individual brainstem section even in the case of neighboring cells. Examples are illustrated (see Figs. 4-8) wherein neurons from control and AS-carbachol cats exhibited different intensities of staining. Fos-immunoreactive (Fos + ) neurons were intermingled with neurons that did not express c-fos. Glial cells in the vicinity of the cannula track and ependymal cells, as described by Menétrey et al. (1989), also exhibited nuclear Fos immunoreactivity.

\section{Distribution of c-fos immunoreactivity}

Cell counts were performed in 51 pontine and medullary structures. These structures are labeled in the schematics of Figure 2 (for the purpose of orientation, note that these schematics are comparable to those seen in Figs. 4-6). The data in Tables 1 and 2 present a comparison of the mean number of Fos + neurons in each structure in control versus AS-carbachol cats. The mean number $( \pm S D)$ of Fos + cells in all structures in the control cats was $1086 \pm 97$ versus $2992 \pm 115$ for the AS-carbachol cats. This overall difference is statistically significant $\left(F_{(1,4)}=\right.$ $363, p=0.0003$ ). This implies that at least some structures must differ beyond chance between the two groups. The structure- specific $p$ values in Tables 1 and 2 are presented for illustrative purpose, with the understanding that they were not produced by a MANOVA model and therefore do not reflect any overall control of the type I error rate.

\section{Reticular formation}

Because different authors have employed diverse nomenclatures for the same structures within the brainstem reticular formation (RF), and because some of the boundaries between these structures cannot be clearly demarcated, the data are described according to a simple regional classification.

As depicted in the schematic of Figure $3 A$, the brainstem RF was divided into midbrain, pontine, and medullary areas according to the following criteria: the boundaries between the midbrain and the pons were the colliculi dorsally and the cerebral peduncles ventrally; the boundary between the pons and medulla was the caudal border of the abducens nucleus. A sagittal plane, $2 \mathrm{~mm}$ from the midline (dashed lines of Fig. $3 B$ ), divided the RF into a medial and a lateral region. The medial pontine RF (MPRF) and medial medullary RF (MMRF) were further divided into a dorsal area (black area in Fig. $3 B$ ) where giant reticular cells are present and a ventral region (hatched area in Fig. $3 B$ ) that is devoid of these cells. One exception to the above-mentioned classification was the caudal portion of the medullary RF at the level of the hypoglossal nucleus (not shown). At this medullary area, the paramedian (PRN) and the lateral reticular nuclei (LRN) are well delineated and reference to them is widely used by brainstem anatomists and physiologists (Taber, 1961). Areas of the medullary RF lateral to the PRN and dorsal to the LRN were designated as the lateral medullary RF (LMRF).

Pons. The distribution of Fos + neurons in the pons of representative control and AS-carbachol cats is illustrated in Figures 4 and 5, left and right, respectively.

In the MPRF, the control cats exhibited, bilaterally, only a 
Table 2. Mean number of Fos + neurons in structures of the pons and medulla during wakefulness and AS-carbachol

\begin{tabular}{|c|c|c|}
\hline \multirow[b]{2}{*}{ Structure } & Wakefulness & AS-carbachol \\
\hline & Mean $\pm \operatorname{SEM}(N)$ & Mean $\pm \operatorname{SEM}(N)$ \\
\hline Abducens motor nucleus & $1 \pm 1.5$ & $17 \pm 8.2$ \\
\hline Central gray* & $14 \pm 5.5$ & $165 \pm 12$ \\
\hline Cuneatus and gracilis nuclei & $14 \pm 0.0$ & $12 \pm 4.4$ \\
\hline Dorsal motor nucleus of the vagus & $13 \pm 3.0$ & $15 \pm 7.0$ \\
\hline Facial motor nucleus* & $37 \pm 2.5$ & $3 \pm 0.6$ \\
\hline Hypoglossal motor nucleus* & $8 \pm 2.0$ & $0 \pm 0.3$ \\
\hline Lateral lemniscus nucleus & $0 \pm 0.5$ & $3 \pm 3.5$ \\
\hline Latero-dorsal tegmental nucleus & $12 \pm 3.5$ & $69 \pm 19.5(2)$ \\
\hline Locus coeruleus & $43 \pm 15$ & $68 \pm 10.5(2)$ \\
\hline Masseter motor nucleus & $15 \pm 8$ & $3 \pm 2.5$ \\
\hline Nucleus intercalatus* & $0 \pm 0.0$ & $10 \pm 0.6$ \\
\hline Nucleus parabrachialis lateralis & $44 \pm 24.5(2)$ & $62 \pm 19.5(2)$ \\
\hline Nucleus parabrachialis medialis* & $16 \pm 0.5$ & $37 \pm 4$ \\
\hline \multicolumn{3}{|l|}{ Nucleus prepositus hypoglossi } \\
\hline$P-6^{*}$ & $5 \pm 1.5$ & $26 \pm 4.5$ \\
\hline $\mathrm{P}-8^{*}$ & $8 \pm 4.5$ & $39 \pm 4.4$ \\
\hline Nucleus of the solitary tract & $17 \pm 5.0$ & $28 \pm 17.7(3)$ \\
\hline \multicolumn{3}{|l|}{ Nucleus nervi sensibilis trigemini } \\
\hline Principalis & $0 \pm 0.0$ & $0 \pm 0.3$ \\
\hline \multicolumn{3}{|l|}{ Nucleus tractus spinalis trigemini } \\
\hline Interpolaris & $9 \pm 5.5$ & $6 \pm 1.9$ \\
\hline \multicolumn{3}{|l|}{ Nucleus tractus spinalis trigemini } \\
\hline \multicolumn{3}{|l|}{ Oralis } \\
\hline$P-6$ & $0 \pm 0.0$ & $0 \pm 0.3$ \\
\hline$P-8$ & $0 \pm 0.0$ & $2 \pm 1.7$ \\
\hline \multicolumn{3}{|l|}{ Nuclcus of the trapezoid body } \\
\hline$P-4.5$ & $26.5 \pm 2.5$ & $47.6 \pm 16.3(3)$ \\
\hline$P-6$ & $22 \pm 0.0$ & $31 \pm 13.6(3)$ \\
\hline Nucleus X & $18 \pm 0.5$ & $18 \pm 3.4$ \\
\hline Pontine gray & $228 \pm 12$ & $214 \pm 24$ \\
\hline Raphe centralis superior* & $46 \pm 1$ & $117 \pm 15$ \\
\hline Raphe dorsalis* & $21 \pm 2$ & $42 \pm 4$ \\
\hline \multicolumn{3}{|l|}{ Raphe magnus } \\
\hline$P-6^{*}$ & $10 \pm 0.5$ & $39 \pm 6.6$ \\
\hline$P-8$ & $6 \pm 3.5$ & $15 \pm 1.4$ \\
\hline \multicolumn{3}{|l|}{ Raphe obscurus } \\
\hline$P-8$ & $0 \pm 0.5$ & $1 \pm 0.7$ \\
\hline $\mathrm{P}-12.5^{*}$ & $5 \pm 0.0$ & $12 \pm 1.4$ \\
\hline \multicolumn{3}{|l|}{ Raphe pallidus } \\
\hline$P-8$ & $25 \pm 1.5$ & $58 \pm 8.9$ \\
\hline$P-12.5$ & $4 \pm 2$ & $11 \pm 3.4$ \\
\hline Raphe pontis & $6.5 \pm 4.5$ & $23.5 \pm 3.5$ \\
\hline \multicolumn{3}{|l|}{ Superior olive } \\
\hline $\mathrm{P}-4.5$ & $1 \pm 1$ & $5 \pm 3.5$ \\
\hline$P-6$ & $0 \pm 0.5$ & $4 \pm 3.2$ \\
\hline Tegmental reticular nucleus & $11 \pm 4.5$ & $57 \pm 38$ \\
\hline \multicolumn{3}{|l|}{ Vestibular nuclei } \\
\hline$P-6$ & $0 \pm 0.0$ & $26 \pm 19.8(3)$ \\
\hline$P-8$ & $0 \pm 0.0$ & $180 \pm 98.8(3)$ \\
\hline
\end{tabular}

Values are means \pm SEM. Stereotaxic coordinates according to Berman (1968).

${ }^{*} p<0.05$ according to Student's $t$ test. Further statistical details are given in the Results.

few scattered Fos + neurons. As depicted in Figure 4, left, the maximum concentration of labeled cells was found in the vicinity of the site of saline injection (indicated by an arrow). At more caudal pontine levels, there were fewer numbers of Fos + neurons in the MPRF (Fig. $5 A, B$, left). In the lateral pontine
RF (LPRF), the control cats exhibited scattered Fos + neurons within a region ventral to the locus coeruleus (LC) and medial to the medial parabrachial nuclei (PBM) and to $\mathrm{nV}$ (Figs. 4, $5 A$, left).

In AS-carbachol cats, large numbers of Fos + neurons were 
Figure 3. Parasagittal $(A)$ and pontine frontal $(B)$ schematics of the brainstem that illustrate the rostrocaudal and mediolateral regional divisions of the RF utilized in the present study. The dashed lines in $A$ indicate the rostral and caudal boundaries of the pontine RF. The medullary RF extends from the caudal border of the abducens nucleus to the medulla-spinal cord junction. The dashed lines in $B$ indicate the mediolateral extension of the medial RF, which is further divided in a dorsal (black) and a ventral (hatched) region. The lateral RF is the dotted region.
A

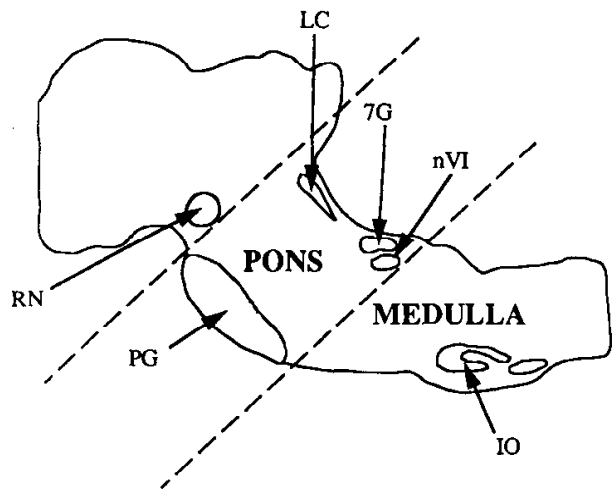

B

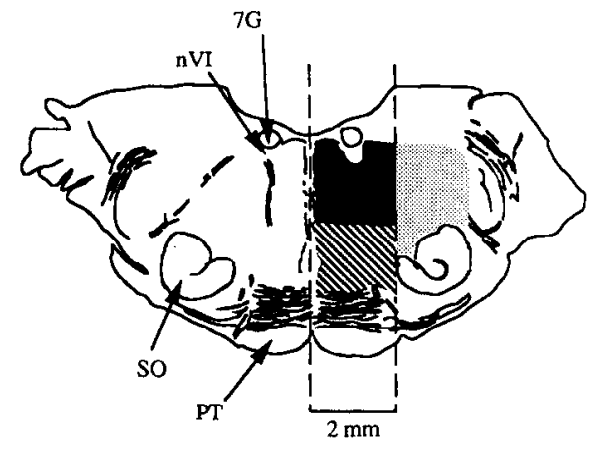

observed bilatcrally throughout the MPRF (Figs. 4; $5 A, B$, right column). Fos-labeled cells were particularly concentrated in the medial third of this region, on the left side, which was the site of carbachol injection (indicated by the arrow of Fig. 4, right). More posteriorly, at the level of $\mathrm{nV}$, high numbers of Fos + neurons were observed (Fig. $5 \mathrm{~A}$, right). At the caudal pontine level, AS-carbachol cats exhibited a higher concentration of Foslabeled neurons within the MPRF, medial to the superior olives and within fascicles of the abducens roots (Fig. $5 B$, right). Additionally, clusters of Fos + cells were found ventrally to nVI (Fig. $5 B$, right).

Whereas high numbers of Fos + neurons were found in the LPRF of AS-carbachol cats at the rostral and medial levels of the pons (Figs. $4,5 A$, right), a few Fos-labeled cells were present in the LPRF at the level of nVI (Fig. $5 B$, right).

The pontomedullary RF contains neurons of different morphological types. According to their size, neurons can be classified as small, medium, large, and giant (Taber, 1961). In both control and AS-carbachol cats, pontine RF neurons that expressed c-fos were predominantly of medium to small size and exhibited various shapes (oval, round, multipolar). Large, multipolar Fos + neurons were observed in the ventral aspects of the caudal MPRF; they were predominantly found in AS-carbachol cats. Giant neurons of the dorsal MPRF were not labeled in the AS-carbachol cats. Only one control cat exhibited a few giant cells that expressed c-fos, and these were located in the immediate vicinity of the injection cannula.

Quantitative data obtained from cell counts in different portions of the pontine RF confirmed that AS-carbachol cats exhibited a larger mean number of Fos + neurons than control cats throughout the MPRF and in the LPRF at the level of $n V$. These data are presented in detail in Table 1.

Medulla. The distribution of Fos + reticular neurons drawn from sections through nVII and nXII of control and AS-carbachol cats is illustrated in Figure 6 . As depicted in the schematic of Figure $6 \mathrm{~A}$, left, control cats exhibited scattered Fos + neurons in the ventral MMRF, whereas only a few Fos-labeled neurons were observed in the dorsal MMRF. Neurons expressing $c$-fos were located bilaterally.

At the level of $n$ VII, AS-carbachol cats exhibited a widespread distribution of Fos+ neurons in the dorsal MMRF, ipsilateral to the injection of carbachol (Fig. 6A, right). In addition, in the ventral MMRF, high concentrations of Fos + neurons were found bilaterally (Fig. 6A, right). In particular, clusters of c-fos-expressing cells were observed near the medial border of $\mathrm{nVII}$ and the lateral border of raphe magnus (RM) and raphe pallidus (RPa). In the LMRF, both control and AS-carbachol cats exhibited only a few scattered Fos + neurons (Fig. 6A, left and right, respectively).

As described above for the pontine RF, medullary reticular

\section{CONTROL CARBACHOL}

Pons ( $\mathrm{P}-2.5)$

Figure 4. Distribution of Fos + neurons in the rostral pons of a control (left) and AS-carbachol (right) cat. The arrows point to the areas of saline (left) and carbachol (right) injections. Each schematic includes Fos-labeled neurons from four superimposed, $7-\mu \mathrm{m}$ thick, adjacent sections selected from $P$ -2.5 , according to Berman (1968). Each dot represents one Fos-labeled cell. To locate the main anatomical structures found at this brainstem level, refer to Figure $2 A$. For further details, see Results and Tables 1 and 2. Scale bars, 1 $\mathrm{mm}$.

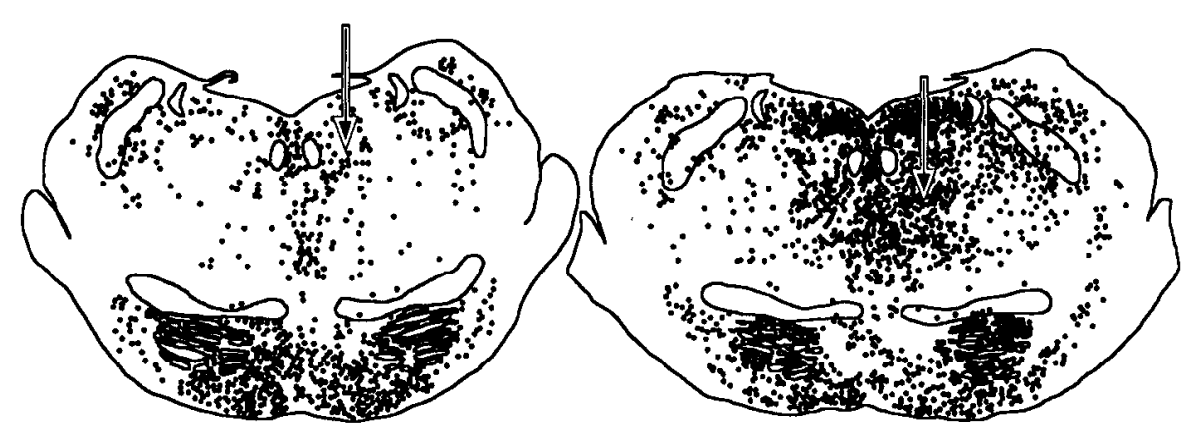




\section{CONTROL CARBACHOL}

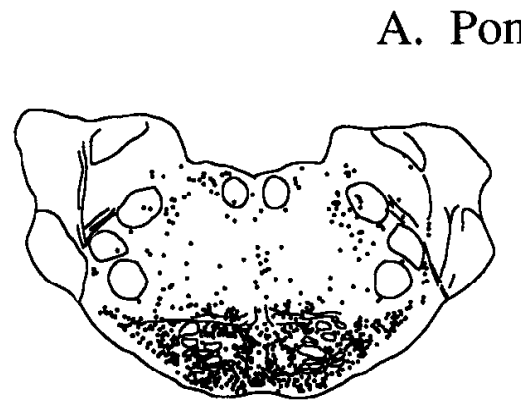

B. Pons $(\mathrm{P}-6)$

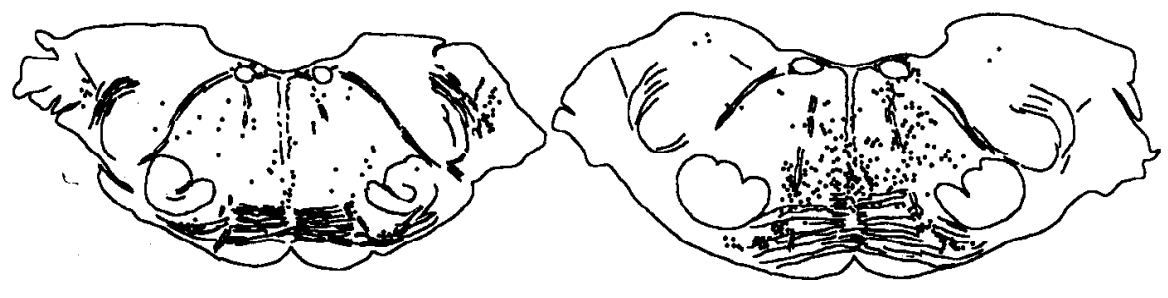

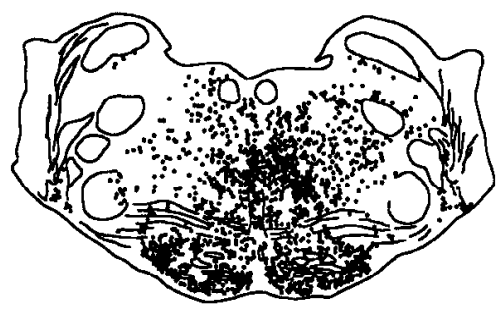

Figure 5. Distribution of Fos+ neurons in the pons, at the level of the masseter $(A)$ and the abducens $(B)$ motor nuclei of a control (left) and AS-carbachol (right) cat. Each schematic includes Fos-labeled neurons from four superimposed, $7-\mu \mathrm{m}$-thick, adjacent sections selected from $P-4.5$ and $P$ -6 , according to Berman (1968). Each $d o t$ represents one Fos-labeled cell. To locate the main anatomical structures found at these brainstem levels, refer to Figure $2 B$ and $C$. For further details, see Results and Tables 1 and 2. Scale bars, $1 \mathrm{~mm}$. neurons of different shapes and sizes, with the exception of giant cells, were labeled with the Fos antibody (Fig. $7 A, B$ ). The different types of Fos + neurons found in the ventral MMRF of an AS-carbachol cat are depicted in Figure 8, $A$ and $B$.

The distribution of Fos + neurons in the RF of the caudal medulla is illustrated in the schematics of Figure $6 \mathrm{~B}$. Whereas control cats exhibited few Fos + cells in the PRN, AS-carbachol cats exhibited Fos + neurons throughout this nucleus. In addition, as depicted in Figure $6 B$, right, clusters of Fos + cells were found in the PRN, dorsal to the inferior olives. Some of the Fos + PRN neurons were observed interspersed within fascicles of the roots of nXII (Fig. $6 B$, right).

In the LMRF, control and AS-carbachol cats exhibited a similar pattern of scattered Fos + neurons (Fig. $6 B$ ). In both groups

\section{CONTROL CARBACHOL}

A. Medulla (P -8)

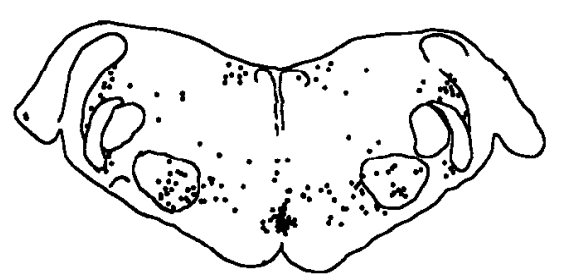

B. Medulla (P-12.5)
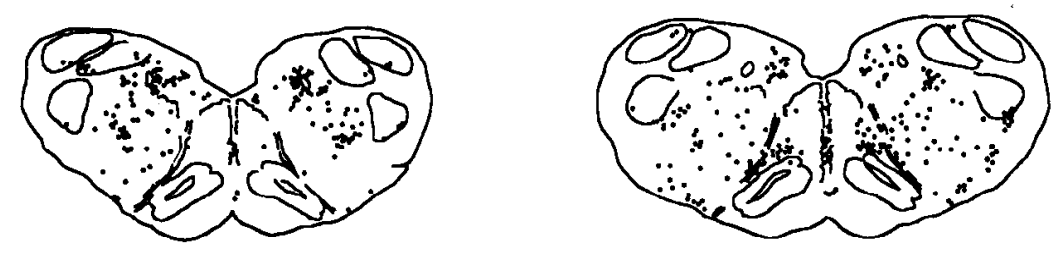

-

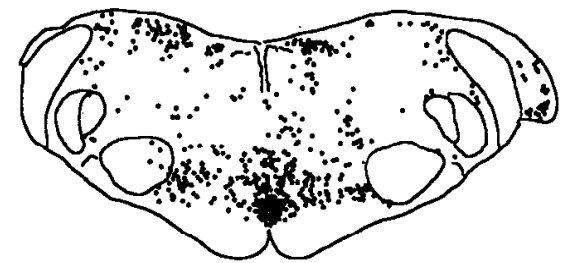

Figure 6. Distribution of Fos + neurons in the medulla, at the level of the facial $(A)$ and the hypoglossal $(B)$ motor nuclei of a control (left) and AS-carbachol (right) cat. Each schematic includes Fos-labeled neurons from four superimposed, 7- $\mu \mathrm{m}$-thick, adjacent sections selected from $P-8$ and $P$ -12.5 , according to Berman (1968). Each dot represents one Fos-labeled cell. To locate the main anatomical structures found at this brainstem level, refer to Figure $2 D$ and $E$. For further details, see Results and Tables 1 and 2. Scale bars, $1 \mathrm{~mm}$. 

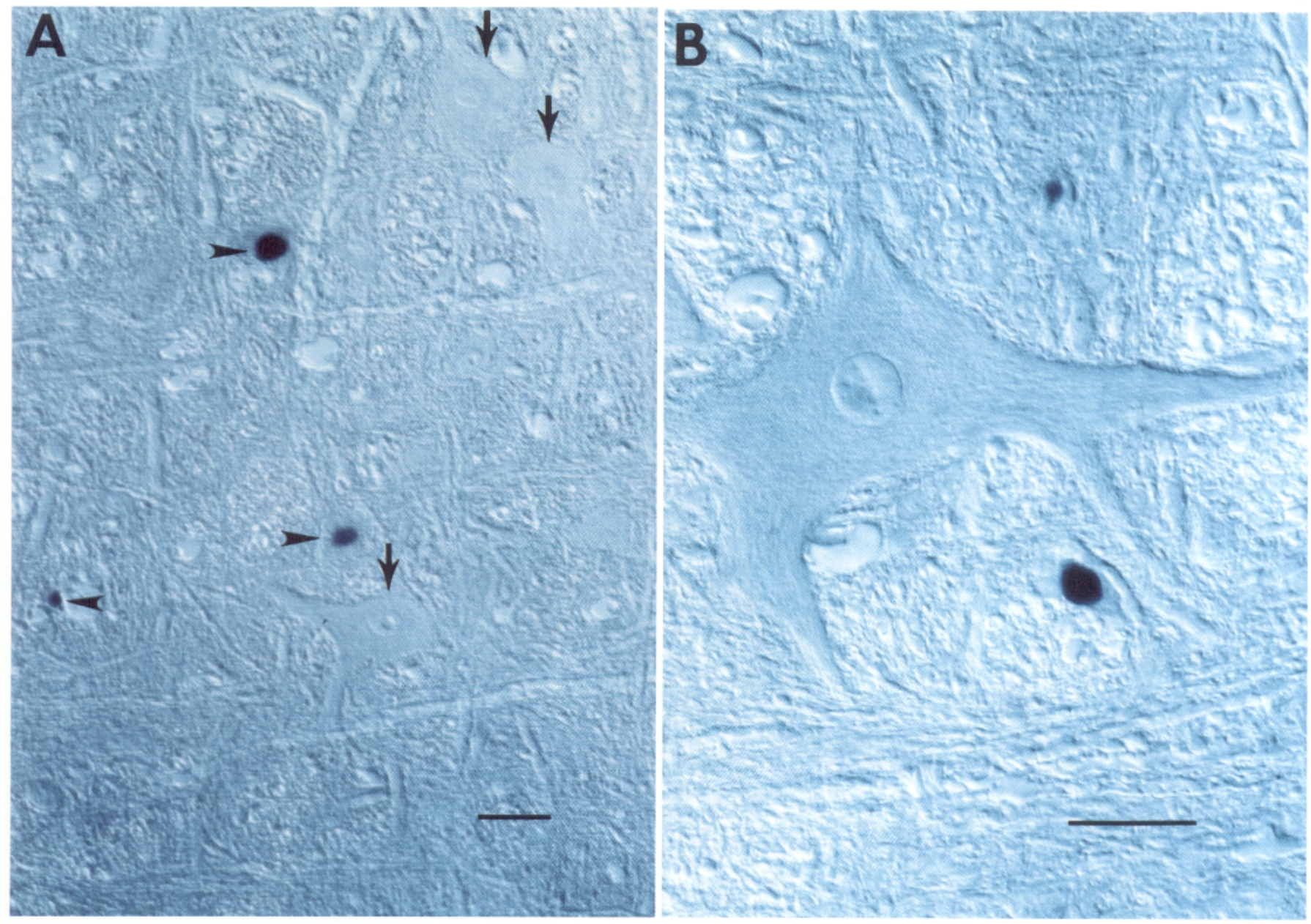

Figure 7. These photomicrographs illustrate Fos immunoreactivity in the dorsal region of the medial RF (dotted rectangle in Fig. 2D) of an AScarbachol cat. Fos-labeled neurons are medium to small size (arrowheads in $A$ ), whereas giant neurons do not exhibit the Fos reaction product (arrows in $A$ ). At higher magnification, a Fos-negative giant cell is flanked by a small Fos-labeled neuron $(B)$. The photomicrographs were taken using Nomarski optics from a medullary section $7 \mu \mathrm{m}$ thick, processed with the alkaline phosphatase method. Scale bars, $40 \mu \mathrm{m}$.

of animals, Fos + cells were found in the nucleus ambiguus. On the other hand, control cats exhibited few Fos + neurons in the LRN and in an area dorsal and medial to the LRN, whereas AS-carbachol cats exhibited scattered Fos-labeled cells in this region (Fig. 6B).

Different types of reticular neurons expressed c-fos in the caudal medulla. For example, Fos-labeled neurons were mostly medium to small size in the PRN of AS-carbachol cats, whereas they were heterogeneous in size and shape within the LRN.

Quantitative data obtained from cell counts in different portions of the medullary RF are presented in detail in Table 1 . AS-carbachol cats exhibited a higher mean number of Fos+ neurons than control cats in all subdivisions of the MMRF (including the PRN) and in the LRN.

\section{Dorsolateral rostral pons}

The dorsolateral aspect of the rostral pons (Fig. $2 A$ ) is a complex region that includes several nuclei, some of which have been implicated in the regulatory mechanisms of active sleep (Jones, 1991). The brainstem level where this region was analyzed corresponds to the location of the roots of MesV and the caudal border of the nucleus of MesV [approximately at P -2.5 , according to Berman's atlas (1968)].
Figure 4 illustrates the patterns of Fos immunoreactivity in representative control and AS-carbachol cats. Compared with control cats, AS-carbachol cats exhibited a larger number of Fos + neurons in the pontine central gray (CG), laterodorsal tegmental nucleus (LDT), LC, the PBM, and the lateral parabrachial nuclei (PBL). Within these nuclei, with the exception of the CG, there were more Fos + cells ipsi- than contralateral to the site of carbachol injection. In fact, the cell count in the nuclei contralateral to carbachol injection yielded numbers similar to those found in control cats.

Fos + cells were predominantly small and round in the CG. More laterally, in the LDT and LC, the morphology of labeled neurons varied (Fig. 9). They were small to medium size and exhibited different shapes (fusiform, round, oval).

\section{Raphe nuclei}

The pontine and medullary raphe nuclei exhibited Fos+ neurons in both AS-carbachol and control cats. The raphe nuclei located in the anterior pons, the dorsal raphe nucleus (RD), and the central superior nucleus exhibited a statistically significant larger number of Fos + neurons in AS-carbachol than in control cats (Table 2). Whereas RD Fos + neurons were medium size (approximately $20 \mu \mathrm{m}$ ) and lightly stained, those from AS- 
carbachol cats were predominantly smaller and more heavily stained.

The group of posterior raphe nuclei [ $\mathrm{RM}, \mathrm{RPa}, \mathrm{RO}$ (raphe obscurus)] exhibited higher mean numbers of Fos + neurons in the AS-carbachol than in the control cats (Table 2). Most of the Fos + neurons from AS-carbachol animals were medium size and their nuclei were heavily stained (Fig. 10).

\section{Vestibular nuclei}

The medial (VMN) and lateral (VLN) vestibular nuclei exhibited Fos + neurons in the AS-carbachol cats, whereas no Foslabeled neurons were observed in vestibular nuclei from control animals. The shape and size of immunoreactive neurons varied (round, oval, multipolar; 12-25 $\mu \mathrm{m}$ soma diameter).

\section{Nucleus prepositus hypoglossi and intercalatus}

Both the nucleus prepositus hypoglossi $(\mathrm{PH})$ and intercalatus (Int) exhibited higher mean numbers of immunoreactive neurons in the AS-carbachol than in the control cats (Table 2). This difference was statistically significant. Fos-labeled cells were usually of small to medium size in these nuclei.

\section{Cranial motor nuclei}

nVII (Fig. 11 $A, B$ ) and nXII motor nuclei from AS-carbachol cats exhibited a lower mean number of Fos + motoneurons than that of control cats (Table 1). nV nuclei from AS-carbachol cats also exhibited fewer Fos-labeled motoneurons than those from control animals. On the other hand, nVI nuclei exhibited more Fos + motoneurons and interneurons in the AS-carbachol than in the control cats (Fig. $11 C, D$ ). The abducens Fos + motoneurons were observed ipsilateral to the site of carbachol microinjection (Fig. 11D).

\section{Discussion}

Pontomedullary regions revealed a consistent pattern of induced $c$-fos expression in neuronal populations that have been previously proposed to be involved in the generation of AS-carbachol and active sleep. In addition, certain neuronal populations that have not been previously implicated in AS-carbachol consistently displayed Fos immunoreactivity in the AS-carbachol cats. We believe that the unique distribution of Fos+ cells in the AS-carbachol cats reflects the excitation of distinct populations of brainstem neurons, whose activation can be directly related to the physiological phenomenology characteristic of carbachol-induced and spontaneously occurring active sleep. The distribution of Fos + neurons will be discussed in the same order as the data were presented in Results.

General considerations regarding c-fos

immunocytochemistry in the present

experimental paradigm

$\mathrm{C}$-fos immunocytochemistry has been reported to be a useful tool for detecting populations of neurons that have been activated; it reaches single-cell resolution, has low background reactivity, and can be combined with other immunocytochemical labelings (Morgan and Curran, 1991).

In spite of the above, the results obtained using c-fos immunocytochemical methods must be carefully evaluated. First, there may be cases of neurons that were activated yet not labeled by the Fos antibody (Dragunow and Faull, 1989). For our purposes, we will term these cells "false negatives." Second, the results of c-fos immunocytochemistry can include Fos + neu-
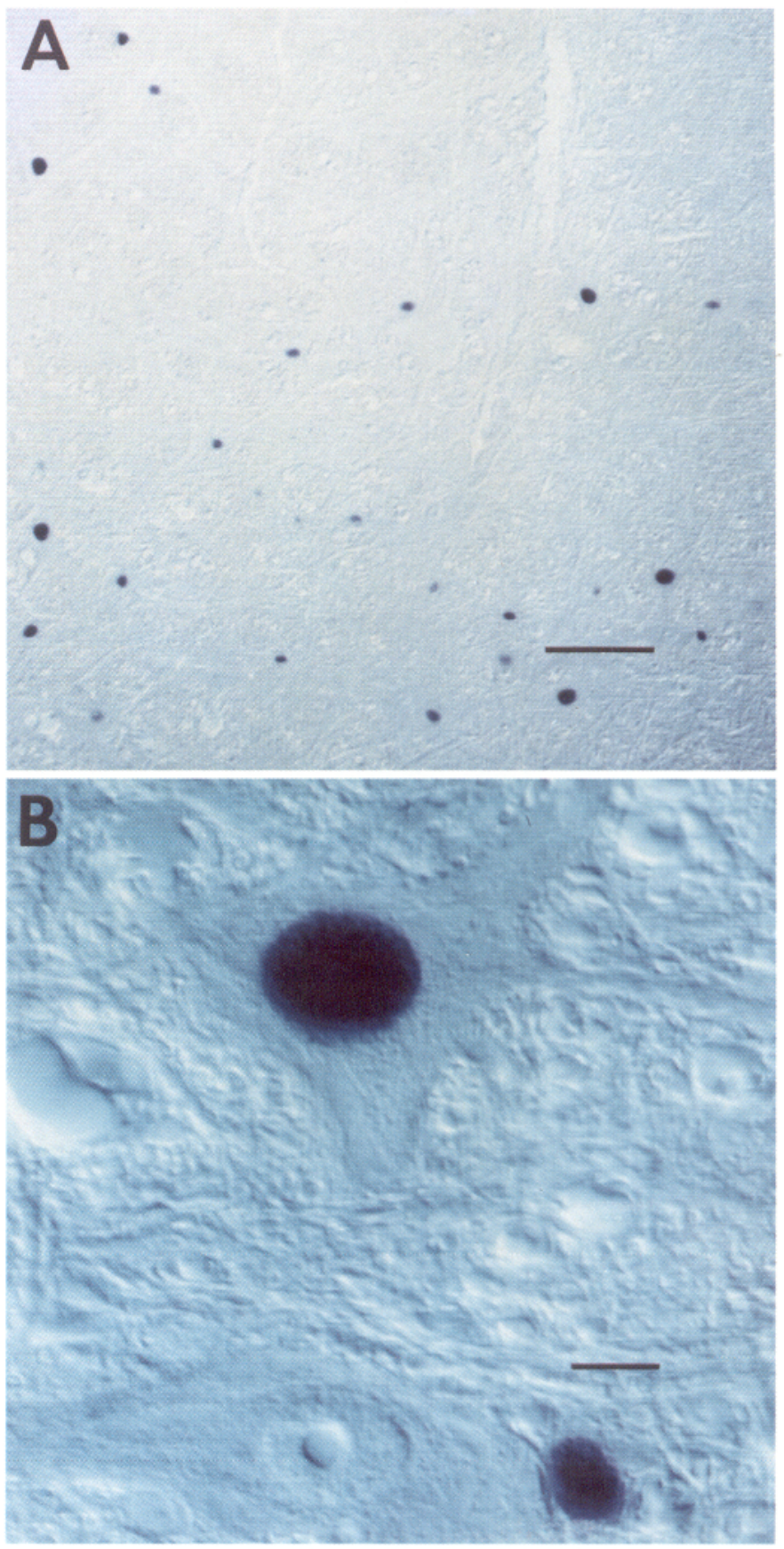

Figure 8. These photomicrographs illustrate Fos + neurons in the ventral region of the medial RF (hatched rectangle in Fig. 2D) of an AScarbachol cat. Note the high number of Fos-labeled neurons in this region $(A)$. A large, multipolar reticular neuron exhibits Fos immunoreactivity, whereas another adjacent large neuron lacks the Fos reaction product $(B)$. The photomicrographs were taken using Nomarski optics from a medullary section $7 \mu \mathrm{m}$ thick, processed with the alkaline phosphatase method. Scale bars: $A, 100 \mu \mathrm{m} ; B, 10 \mu \mathrm{m}$.

rons whose activation is not related to the stimulus under study. For our purposes, we will term these cells "false positives." For example, it is possible that a subpopulation of Fos + neurons were activated directly or transynaptically by carbachol and were not related to the AS-carbachol state. Furthermore, it has been shown that stress, produced by handling of the experimental animal, can induce c-fos expression in neurons of certain 

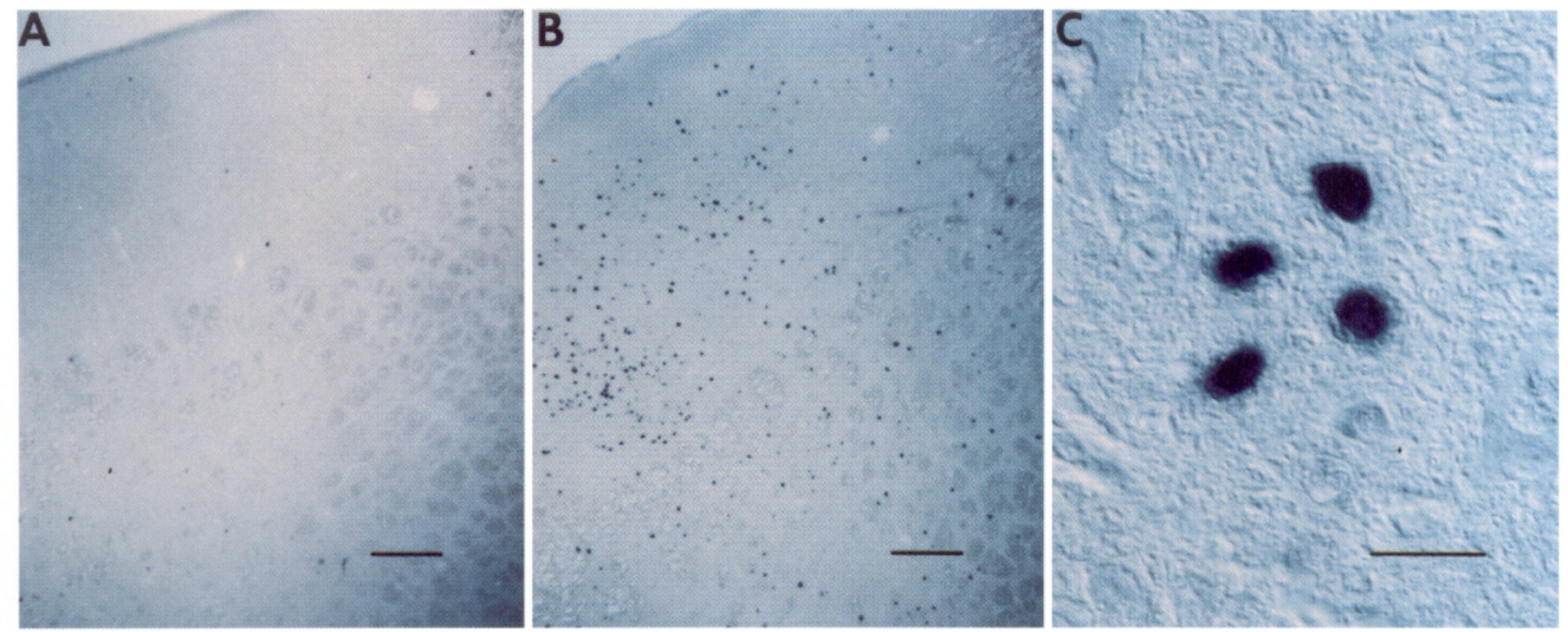

Figure 9. These photomicrographs illustrate Fos + neurons in the dorsal aspect of the rostral pontine tegmentum (rectangle with vertical bars in Fig. $2 A)$, at the level of the roots of the trigeminal mesencephalic nucleus of a control $(A)$ and an AS-carbachol $(B$ and $C)$ cat. Note the high concentration of Fos-labeled neurons exhibited in this region by the AS-carbachol cat. Fos + neurons from the laterodorsal tegmental nucleus are illustrated at a high magnification in $C$. The photomicrographs were taken using Nomarski optics from a pontine section $7 \mu \mathrm{m}$ thick, processed with the alkaline phosphatase method. Scale bars: $A$ and $B, 200 \mu \mathrm{m} ; C, 20 \mu \mathrm{m}$.

areas of the CNS, including some brainstem nuclei (Ceccatelli et al., 1989). Additionally, it has been reported that surgical procedures induce neuronal c-fos expression in sensory regions of the dorsal horn (Hunt et al., 1987) and that brain tissue damage elicits c-fos expression in glial as well as nerve cells (Dragunow and Faull, 1989; Sharp et al., 1989).

Thus, a carefully designed experimental protocol is required in order to avoid the above-mentioned caveats (Dragunow and Faull, 1989). In the present study, all cats were treated similarly prior to and during the experiment. The time between microinjection and the fixation of the tissue was selected in order to allow for a high level of Fos expression. Care was taken to adapt the cats to the experimental apparatus in order to avoid stressful conditions. In addition, no surgical procedures were performed during the $36 \mathrm{hr}$ prior to the experiment in order to assure that c-fos expression had returned to a basal level (Dragunow and Faull, 1989).

Given the experimental design used, we believe that the different distribution of Fos + cells exhibited by the AS-carbachol compared with that from the control cats reflects the excitation of distinct populations of brainstem neurons and that the activation of some of the cells from these populations is causally related to the phenomena characteristic of the AS-carbachol state. The observation that Fos immunoreactivity of both groups of cats had a discrete distribution within certain structures is consistent with this interpretation and will be discussed below.

\section{Reticular formation}

We believe that the widespread pattern of distribution of Fos+ neurons that occurs in the RF during AS-carbachol reflects the activation of populations of neurons that subserve diverse statedependent functions that occur during this state. In this regard, the present results confirm and extend previous studies that indicate that various neuronal populations of the pontine and medullary RF are implicated in the generation and maintenance of AS-carbachol and active sleep, as discussed below.
Pontine reticular formation. Fos + cells were observed in the dorsolateral aspect of the MPRF, in a region where carbachol injections are most effective in producing AS-carbachol (VanniMercier et al., 1989; Yamamoto et al., 1990a). The presence of activated cells, as determined by their c-fos expression, agrees with previous data that indicate that a subpopulation of cells recorded in this area increase their rate of discharge following local carbachol administration as well as during naturally occurring active sleep (Shiromani and McGinty, 1986; Yamamoto, 1990b). It has been proposed that this pontine region, within or in the vicinity of the nucleus reticularis pontis oralis, is involved in the generation of the atonia of active sleep (Chase, 1976, 1983; Mori, 1987; Chase and Morales, 1990). Sakai (1988) and Sakai et al. (1981) have reported that this region, which they define as the peri-locus coeruleus $\alpha$, contains neurons that discharge both selectively and tonically during active sleep. Fos + neurons in this area of the dorsolateral MPRF were of medium to small size. This finding is in accord with the characteristics of neurons in this region that project to the motor inhibitory area of the medulla (Sakai et al., 1979), where cells have also been reported to discharge in an active sleep-dependent fashion (Chase et al., 1981; Sakai, 1988). We therefore propose that Fos + neurons, which were found in high numbers in the dorsolateral aspect of the MPRF, correspond to the cholinoceptive cells that are responsible for the generation of atonia during AScarbachol and active sleep.

Fos + neurons were also observed in high concentrations throughout the MPRF of AS-carbachol cats in areas that correspond to the gigantocellular tegmental field (FTG) of Berman (1968) and to the medial portion of the nucleus reticularis pontis caudalis (Taber, 1961). Such a profuse distribution of Fos+ neurons raises two questions: (1) is the activation of these neurons related to AS-carbachol and active sleep processes, and (2) by which means are these neurons activated?

With regard to the first question, the present data are in agree- 

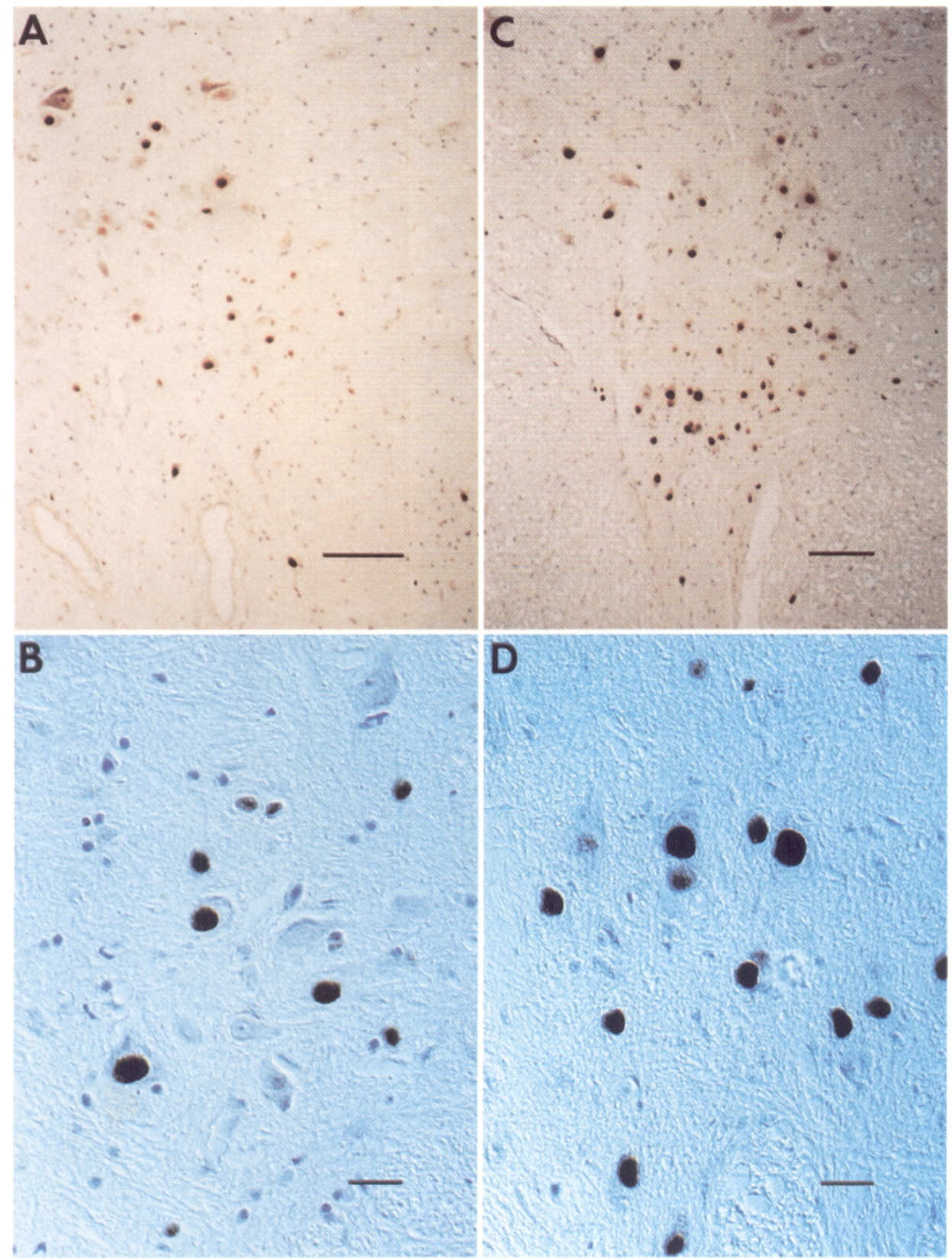

Figure 10. These photomicrographs illustrate Fos + neurons in the RM and RP of a control $(A$ and $B)$ and an AScarbachol $(C$ and $D)$ cat. Note that more Fos-labeled neurons are found in the carbachol-induced state than in control cats. The photomicrographs were taken using Nomarski optics from a medullary section $7 \mu \mathrm{m}$ thick, processed with the diaminobenzidine method and counterstained with cresyl violet. Scale bars: $A$ and $C, 100 \mu \mathrm{m} ; B$ and $D, 20$ $\mu \mathrm{m}$.

ment with studies that report that neurons in the MPRF increase their rate of discharge during AS-carbachol in the chronic, freebehaving cat (Shiromani and McGinty, 1986) and during the atonic state induced by the systemic administration of eserine in the decerebrate cat (Pompeiano and Hoshino, 1976). However, cells in the MPRF also increase their rate of discharge in relation to movements during both active sleep and wakefulness (Siegel and McGinty, 1977; Vertes, 1979). It is also important to note that chemical or electrolytic destruction of the MPRF does not eliminate the occurrence of active sleep (Sastre et al., 1981). Thus, although Fos + cells within the MPRF may become activated during AS-carbachol and active sleep, they are apparently not responsible for the generation of these states.

We believe, for the following reasons, that a subpopulation of the Fos + neurons were cholinoceptive and activated directly by carbachol. The existence of cholinoceptive neurons in the MPRF is indicated by the presence of cholinergic afferents that terminate in juxtaposition to reticular neurons (Jones, 1990). It has been reported that these cholinergic fibers originate from the LDT and pedunculopontine tegmental nucleus (PPT) (Mitani et al., 1988; Jones, 1990) and from cholinergic neurons located in the medullary RF (Jones, 1990). Moreover, Greene and Carpenter (1985) have shown that the microiontophoresis of ACh excites a subset of pontine reticular neurons; however, their experiments were restricted to the caudal part of the nucleus reticularis pontis caudalis ventral to the nVI nucleus. It is also possible that some reticular Fos + neurons were excited transynaptically by afferents originating in the LDT because this nucleus exhibited Fos-labeled cells in AS-carbachol cats (see below). Additionally, a subpopulation of MPRF neurons may have been activated transynaptically through local reticular circuits (Valverde, 1961).

In the caudal pons of AS-carbachol cats, clusters of neurons were present in a region adjacent to the ventral border of the 


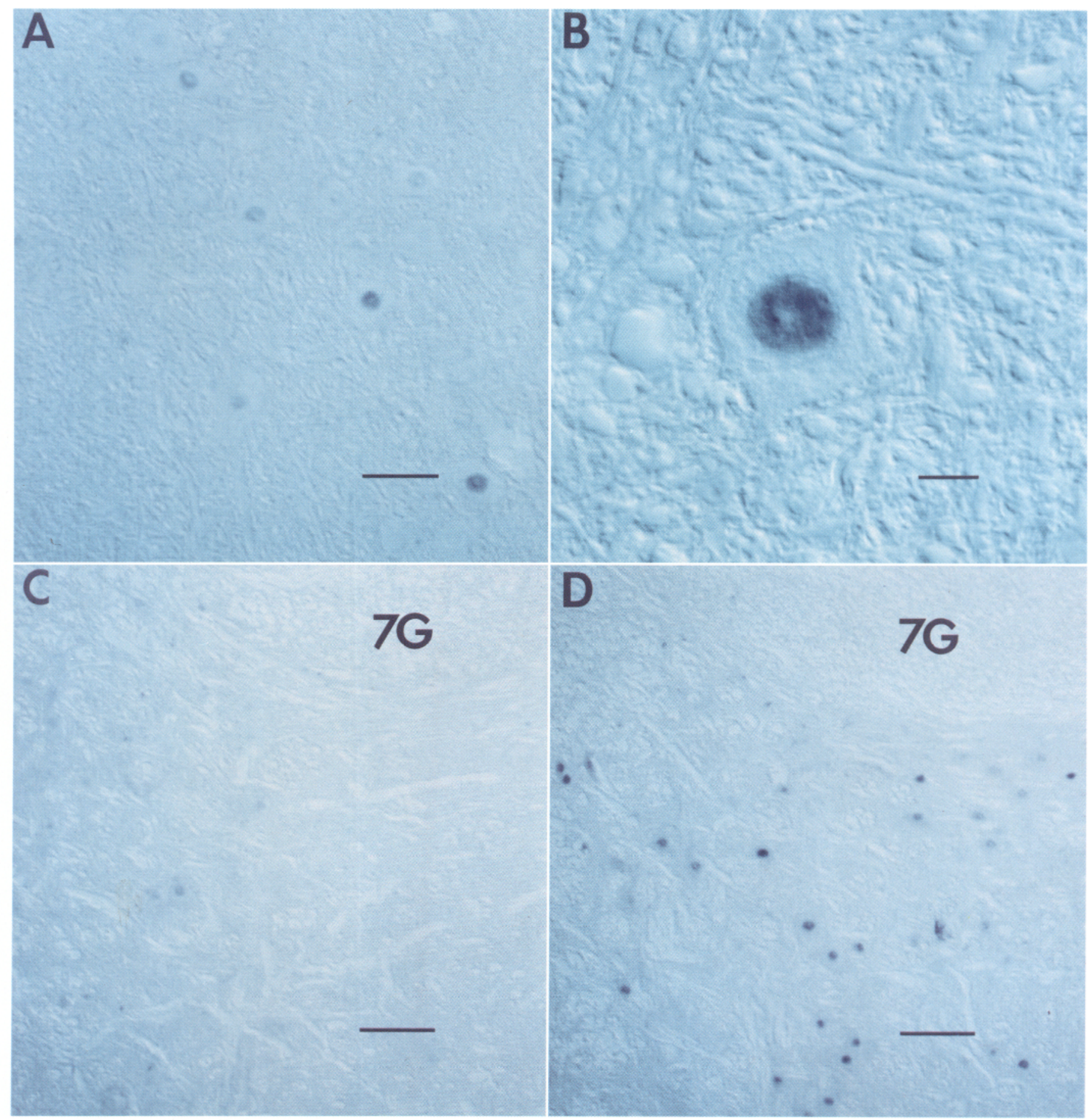

Figure 11. These photomicrographs illustrate cranial motor nuclei Fos immunoreactivity in control and AS-carbachol cats. Facial motoneurons expressed c-fos in control cats $(A$ and $B)$. One abducens motoneuron from a control cat exhibits light Fos immunoreactivity $(C)$, whereas the AScarbachol cat exhibits large numbers of Fos-labeled motoneurons ipsilateral to the carbachol injection site $(D)$. $7 G$, genu of the facial nerve. The photomicrographs were taken using Nomarski optics from brainstem sections $7 \mu \mathrm{m}$ thick, processed with the alkaline phosphatase method. Scale bars: $A, 50 \mu \mathrm{m} ; B, 10 \mu \mathrm{m} ; C$ and $D, 100 \mu \mathrm{m}$.

nVI nucleus. This area, which contains neurons that project rostrally to the oculomotor complex, has been implicated in the mechanisms of conjugated eye movements (Graybiel and Hartwieg, 1974; Graybiel, 1977). Additionally, it has been reported that the microinjection of carbachol into the dorsal FTG, in the vicinity of the nVI nucleus, elicits PGO-like bursts that are related to nystagmic eye movements (Vanni-Mercier et al., 1989).
It is therefore likely that the Fos-labeled cells found in this area participate in the generation of rapid eye movements during AS-carbachol and active sleep.

Fos+ neurons in the MPRF were predominantly medium to small size and their somas were of different shapes. Large, multipolar type cells were found in the ventral aspects of the MPRF. Whereas giant reticular neurons of control cats expressed c-fos 
only rarely, Fos + giant cells were not found in the AS-carbachol cats. It is interesting to note that even those giant reticular neurons that were in close proximity to the site of carbachol injection did not express c-fos, even though immunocytochemical and iontophoretic studies have indicated that giant cells are cholinoceptive (Greene and Carpenter, 1985; Jones, 1990).

Giant cells have been postulated to be selectively activated and involved in the generation of active sleep in head-restrained cats (McCarley and Hobson, 1975). However, in free-behaving unrestrained cats, the activity of gigantocellular field neurons was correlated with movements that occurred during both active sleep and wakefulness (Siegel and McGinty, 1977; Siegel et al., 1979). It should be noted that these neurons were not anatomically identified as giant cells in the above-mentioned investigations (McCarley and Hobson, 1975; Siegel and McGinty, 1977; Siegel et al., 1979). The finding that they do not express c-fos during AS-carbachol suggests that giant cells do not play a critical role in this behavioral state; it is also possible that their activation was not detected by Fos immunocytochemistry.

Medullary reticular formation. In brainstem sections passing through the mid-portion of the nVII nucleus there were, bilaterally, a larger number of Fos-labeled neurons in the MMRF region in AS-carbachol than in control cats. This caudal portion of the medial RF encompasses the motor inhibitory area originally described by Magoun and Rhines (1946) and others (Llinas and Terzuolo, 1964, 1965; Jankowska et al., 1968). In addition, this area has been related to AS-carbachol and active sleep processes by authors using diverse experimental paradigms. In the dorsal aspect of the MMRF, which corresponds to the nucleus reticularis gigantocellularis (NRGc), intracellular (Chase et al., 1981) and unit recordings (Shiromani and McGinty, 1986) have shown that neurons increase their rate of discharge during active sleep. It has been reported that electrical stimulation of the NRGc elicits active sleep-specific postsynaptic inhibition in cranial and lumbar motoneurons (Chase et al., 1986). Additionally, using the spike-trigger averaging technique, Takakusaki et al. (1989) have reported that the discharge of glutamate-stimulated neurons of the NRGc elicits disynaptic IPSPs in lumbar motoneurons, and that these NRGc neurons discharge following the electrical stimulation of fibers that are purported to originate in the dorsolateral pontine tegmentum (Ohta et al., 1988).

In the ventral region of the MMRF, medially to nVII, AScarbachol cats exhibited bilaterally a great number of Fos-labeled cells. This region has been related to the generation of atonia during active sleep (Sakai et al., 1979); in addition, glutamate ejections in this region elicit neck muscle atonia both in the decerebrate and in the unrestrained cat (Lai and Siegel, 1988). Unit recordings have also disclosed a positive correlation between neuronal discharge and the appearance of active sleep atonia (Sakai et al., 1981; Sakai, 1988).

Recently, glycine-immunorcactive ncurons have been observed in a ventral medullary RF area medial to the $\mathrm{nVII}$ motor nucleus (Fort et al., 1990), where a high concentration of Fos + neurons was observed. If these glycine-immunoreactive cells are the same as the AS-carbachol Fos + neurons described in the present study, they would be candidate cells for the production of the postsynaptic glycinergic inhibition of cranial motoneurons that occurs during active sleep (Chase et al., 1989; Soja et al., 1990).

The caudal portion of the MMRF, which includes the PRN, also exhibited Fos + cell counts that were bilaterally greater in the AS-carbachol than in the control cats. This reticular region represents the caudal extension of Magoun's motor inhibitory region. Lai and Siegel (1988) found that the microinjection of carbachol into this region elicited neck musculature atonia. Furthermore, it has been reported that PRN cells receive direct cholinergic projections that originate in the dorsolateral pontine region (Shiromani et al., 1990) that has also been implicated in the atonia of active sleep; in AS-carbachol cats this region exhibited a high concentration of Fos + neurons.

The ventrolateral aspect of the medullary RF, including the LRN, also exhibited more Fos + neurons in the AS-carbachol than in the control cats. Sites in this region have been implicated in the control of cardiovascular (for review, see Owman, 1986) and respiratory (for review, see Feldman, 1986) functions. It has also been well established that cardiovascular and respiratory changes occur during active sleep (for review, see Vertes, 1984). The present data therefore suggest that cells within these sites, which are involved in autonomic regulation, become activated during AS-carbachol.

\section{Dorsolateral rostral pons}

The increased immunoreactivity in certain nuclei of the rostral dorsolateral pons during AS-carbachol is in agreement with data that indicate that neurons within this region arc implicated in the generation of AS-carbachol and active sleep (for review, see Jones, 1991). It has been shown that chemical destruction of this region blocks the occurrence of active sleep (Webster and Jones, 1988). This region contains cholinoceptive neurons (Leonard and Llinas, 1990) and is the origin of descending cholinergic pathways that project to sites that have been implicated in the generation of motor suppression during active sleep, such as the dorsolateral MPRF (see above), and to more caudal regions of the MMRF (Sakai, 1988). Furthermore, in the LDT and PBL, neurons discharge in relation to bursts of PGO waves (Jones, 1991). This region is also the origin of ascending pathways implicated in the EEG desynchronization of active sleep (Jones, 1991). Recently, Merchant-Nancy et al. (1992) reported an increased number of Fos-like immunoreactive neurons in the PPT, parabrachial, subcoeruleus, and solitary tract nuclei following REM sleep duration enhancement induced by sleep deprivation or auditory stimulation. However, in contrast to our results (see above), these authors did not find Fos + neurons in the pontine and medullary RF, where neurons have been shown to increase their rate of discharge during active sleep (Sakai et al., 1981; Sakai, 1988).

AS-carbachol Fos + neurons in the dorsolateral pons of cats may be involved in autonomic changes that occur during AScarbachol (Katayama et al., 1984) and active sleep. For example, there are descending enkephalinergic projections to spinal sympathetic nuclei that originate in the ventral $\mathrm{LC}$ and the nucleus subcoeruleus (Romagnano et al., 1991). In addition, the PBM, which have been implicated in the control of cardiovascular and respiratory functions, contain neurons whose firing rates accelerate and become irregular during active sleep (for review, see Vertes, 1984). Thus, their activity mimics the accelerated and irregular pattern of cardiovascular activity that occurs during this behavioral state.

\section{Raphe nuclei}

Several raphe nuclei exhibited a significantly higher number of Fos + cells in the AS-carbachol than in the control cats. These 
raphe nuclei include $\mathrm{RD}$, raphe central superior, $\mathrm{RM}$, and $\mathrm{RO}$ (the latter at the level of the nXII motor nucleus).

Serotonergic neurons of the RD nucleus have been shown to be silent during active sleep (McGinty and-Harper, 1976). However, some of the RD cells are not serotonergic and their pattern of discharge suggests that they are inhibitory to the scrotoncrgic cells (Aghajanian et al., 1978). AS-carbachol cats exhibited Fos+ neurons of small size in the area of the non-serotonergic RD neurons, adjacent to the medial longitudinal fasciculus (Aghajanian et al., 1978). Because electrical stimulation of the MPRF, where carbachol was injected, suppresses the activity of RD serotonergic neurons (Wang et al., 1976), carbachol may have elicited a similar effect by direct or transynaptic activation of non-serotonergic RD neurons, which in turn inhibited the serotonergic raphe cells.

The presence of larger numbers of Fos + neurons in the RM of AS-carbachol than in control cats agrees with data that indicate that a population of RM neurons increase their firing rate during active sleep (Sheu et al., 1974; Cespuglio et al., 1981). Because of the neurotransmitter heterogeneity of the posterior raphe nuclei (Hunt and Lovick, 1982; Romagnano et al., 1991), it is possible that some of the Fos + ncurons in thesc nuclci werc not serotonergic.

\section{Vestibular nuclei}

The present data indicate that neurons in the VMN and VLN are activated during AS-carbachol. The excitation of these vestibular neurons may be related to the phasic motor activity that occurs during this state and active sleep (muscle twitches, rapid eye movements). It has also been reported that VMN units increase their discharge rate in association with rapid eye movements following the systemic administration of eserine (Magherini et al., 1972) and during active sleep (Bizzi et al., 1964).

\section{Nucleus prepositus hypoglossi and intercalatus}

The PH and Int exhibited a larger number of Fos + cells in AScarbachol than in control cats. It has been reported that these nuclei contain premotor neurons that project to oculomotor nuclei (Graybiel and Hartwieg, 1974). In addition, these nuclei receive afferent fibers originating in the paramedian RF (Graybiel, 1977), where AS-carbachol cats exhibited heavy Fos immunoreactivity. Because the medial RF, PH, and Int are involved in oculomotor mechanisms, their activation is most likcly related to the occurrence of eye movements during AS-carbachol. Furthermore, the activation of $\mathrm{PH}$ neurons may be related to PGO activity that is present during AS-carbachol. Higo et al. (1990) have described reciprocal connections between the PH and the PPT, which have been implicated in the mechanisms of PGO wave generation (Steriade and McCarley, 1990).

\section{Cranial motor nuclei}

$\mathrm{nV}, \mathrm{nVII}$, and $\mathrm{nXII}$ motoneurons exhibited a small number of Fos labeling in the control cats, whereas in AS-carbachol cats these motoneurons were rarely labeled. In contrast to this finding, more $\mathrm{nVI}$ motoneurons expressed c-fos in the AS-carbachol cats. These results are in accord with the different behavioral states exhibited by the experimental animals. Whereas nV, nVII, and $\mathrm{nXII}$ motoneurons are inhibited or disfacilitated during active sleep (Chase et al., 1980; Soja, 1991), nVI motoneurons undergo periods of intense activation that result in the characteristic REMs of active sleep.

\section{Conclusions and future directions}

The data reported in the present work represent part of a longterm analysis of the neural networks involved in the generation and preservation of active sleep. The results indicate that c-fos immunoreactivity reflects a pattern of neuronal activation in the brainstem that is specific to the complex behavioral state, AS-carbachol, which mimics naturally occurring active sleep. The activation of neurons in the MPRF and MMRF, dorsolateral rostral pons, VMN and VLN, and thc abducens nuclei, and the decreased number of activated motoneurons in the nVII, $\mathrm{nV}$, and $\mathrm{nXII}$ nuclei are in agreement with results reported in the literature (Siegel, 1989; Chase and Morales, 1990; Steriade and McCarley, 1990; Jones, 1991). The finding that neurons within the LRN and the surrounding LMRF, PH, Int, and various raphe nuclei, were activated during AS-carbachol stresses the need for further work to investigate their role in the mechanisms of AS-carbachol and active sleep. Recently, Lydic et al. (1991) used the metabolic rate of glucose utilization as an indicator of the level of neuronal activity during wakefulness and active sleep in the brain of the cat. These authors found increased glucose uptake in the pontine reticular formation, dorsolateral rostral pons, raphe nuclei, and $\mathrm{PH}$ during active sleep, among other sites in the forebrain. It is interesting to note that, although the glucose utilization technique does not reach single-cell resolution as c-fos immunocytochemistry does, the distribution of activated regions found by Lydic et al. (1991) during active sleep is comparable to the distribution of Fos + neurons during AScarbachol. At the time that this manuscript was being revised for publication, a study related to the present investigation was published. Shiromani et al. (1992) examined Fos-like immunoreactivity in pontine regions slightly rostral to those analyzed here during the REM-like state induced by carbachol microinjection into the pons; their results are in agreement with our data that indicate that neurons within structures of the dorsolateral rostral pons express c-fos during the AS-carbachol state.

Additional studies to increase the sample size and to deliver minute amounts of carbachol in order to better localize the cholinoceptive region responsible for AS-carbachol are currently being undertaken. Furthermore, the use of c-fos immunocytochemistry during spontaneous active sleep should be considered. In addition, the possibility that postsynaptic inhibition may induce c-fos expression in postsynaptic cells (Sharp et al., 1989) should be explored. However, with the exception of abducens motoneurons, which are expected to undergo activation in AScarbachol cats, the decreased c-fos expression in motoneurons that are postsynaptically inhibited during AS-carbachol and active sleep (Chase et al., 1980; Morales et al., 1987) indicates that at lcast some neurons do not express c-fos when they are inhibited.

The combination of c-fos immunocytochemistry with other techniques should help to illuminate the nature and enhance our understanding of the role played by the activated cell populations described in the present work. For example, immunocytochemical double-labeling techniques that provide for the detection of c-fos expression and neurotransmitters can define the biochemical nature of Fos-labeled cells. Orthograde and retrograde tracers and extra- and intracellular recordings from implicated regions may also be combined with c-fos immuno- 
cytochemistry in order to establish the connectivity and functional role of particular types of neurons. Thus, we believe that c-fos immunocytochemistry, especially when combined with other procedurcs, can provide kcy information regarding the physiological and anatomical foundations of active sleep.

\section{References}

Afifi AA, Azen SP (1979) Statistical analysis: a computer oriented approach. New York: Academic.

Aghajanian GK, Wang RY, Baraban J (1978) Serotonergic and nonserotonergic neurons of the dorsal raphe: reciprocal changes in firing induced by peripheral nerve stimulation. Brain Res 153:169-175.

Baghdoyan HA, Rodrigo-Angulo ML, McCarley RW, Hobson JA (1987) A neuroanatomical gradient in the pontine tegmentum for the cholinoceptive induction of desynchronized sleep signs. Brain Res 414:245-261.

Baghdoyan HA, Lydic R, Callaway CW, Hobson JA (1989) The carbachol-induced enhancement of desynchronized sleep signs is dose dependent and antagonized by centrally administered atropine. Neuropsychopharmacology 2:67-79.

Berman AL (1968) The brainstem of the cat. A cytoarchitectonic atlas with stereotaxic coordinates. Madison: University of Wisconsin.

Bizzi E, Pompeiano O, Somogyi I (1964) Vestibular nuclei activity of single neurons during natural sleep and wakefulness. Science 145: $414-415$.

Ceccatelli S, Villar MJ, Goldstein M, Hökfelt T (1989) Expression of c-fos immunorcactivity in transmittcr-characterized ncurons after stress. Proc Natl Acad Sci USA 86:9569-9573.

Cespuglio R, Faradji H, Gomez ME, Jouvet M (1981) Single unit recordings in the nuclei raphe dorsalis and magnus during the sleepwaking cycle of semi-chronic prepared cats. Neurosci Lett 24:133138.

Chase MH (1976) A model of central neural processes controlling motor behavior during active sleep and wakefulness. In: Mechanisms in transmission for signals for conscious behavior (Desiraju $\mathrm{T}$, ed), pp 99-121. Amsterdam: Elsevier.

Chase MH (1983) Synaptic mechanisms and circuitry involved in motoneuron control during sleep. In: International review of neurobiology, Vol 24 (Bradley RJ, ed), pp 213-258. New York: Academic.

Chase MH, Morales FR (1990) The atonia and myoclonia of active (REM) sleep. Annu Rev Psychol 41:557-584.

Chase MH, Chandler SH, Nakamura Y (1980) Intracellular determination of membrane potential of trigeminal motoneurons during sleep and wakefulness. J Neurophysiol 44:349-358.

Chase MH, Enomoto S, Murakami T (1981) Intracellular potential of medullary reticular neurons during sleep and wakefulness. Exp Neurol 71:226-233.

Chase MH, Morales FR, Boxer PA, Fung SJ, Soja PJ (1986) Effect of stimulation of the nucleus reticularis gigantocellularis on the membrane potential of cat lumbar motoneurons during sleep and wakefulness. Brain Res 386:237-244.

Chase MH, Soja PJ, Morales FR (1989) Evidence that glycine mediates the postsynaptic potentials that inhibit lumbar motoneurons during the atonia of active sleep. J Neurosci 9:743-751.

Dragunow M, Faull R (1989) The use of c-fos as a metabolic marker in neuronal pathway tracing. J Neurosci Methods 29:261-265.

Feldman J (1986) Neurophysiology of breathing in mammals. In: Handbook of physiology: the nervous system, Sec 1, Vol 4 (Mountcastle VB, ed), pp 463-524. Bethesda, MD: American Physiological Society.

Fort P, Luppi PH, Wenthold R, Jouvet M (1990) Neurones immunoréactifs à la glycine dans le bulbe rachidien du chat. C R Acad Sci (Paris) 311:205-212.

George R, Haslett WL, Jenden DJ (1964) A cholinergic mechanism in the brainstem reticular formation: induction of paradoxical sleep. Int J Neuropharmacol 3:541-552.

Graybiel AM (1977) Direct and indirect preoculomotor pathways of the brainstem: an autoradiographic study of the pontine reticular formation in the cat. J Comp Neurol 175:37-78.

Graybiel AM, Hartwieg EA (1974) Some afferent connections of the oculomotor complex in the cat: an experimental study with tracer techniques. Brain Res 81:543-551.

Greene RW, Carpenter DO (1985) Actions of neurotransmitters on pontine medial reticular formation neurons of the cat. J Neurophysiol 54:520-531.

Higo S, Ito K, Fuchs D, McCarley RW (1990) Anatomical interconnections of the pedunculopontine tegmental nucleus and the nucleus prepositus hypoglossi in the cat. Brain Res 536:79-85.

Hsu SM, Raine L, Fanger H (1981) A comparative study of the antiperoxidase method and an avidin-biotin complex method for studying polypeptide hormones with radioimmunoassay antibodies. Am J Clin Pathol 75:734-738.

Hunt SP, Lovick TA (1982) The distribution of serotonin, met-enkephalin and $\beta$-lipotropin-like immunoreactivity in neuronal pericarya of the cat brainstem. Neurosci Lett 30:139-145.

Hunt SP, Pini A, Evan E (1987) Induction of c-fos-like protein in spinal cord neurons following sensory stimulation. Nature 328:632634.

Jankowska E, Lund S, Lundberg A, Pompeiano O (1968) Inhibitory effects evoked through ventral reticulospinal pathways. Arch Ital Biol 106:124-140.

Jones BE (1990) Immunohistochemical study of choline acetyltransferase-immunoreactive processes and cells innervating the pontomedullary reticular formation in the rat. J Comp Neurol 295:485514.

Jones BE (1991) Paradoxical sleep and its chemical/structural substrates in the brain. Neuroscience 40:637-656.

Katayama Y, DeWitt DS, Becker DP, Hayes RL (1984) Behavioral evidence for a cholinoceptive pontine inhibitory area: descending control of spinal motor output and sensory input. Brain Res 296: 241-262.

Lai YY, Siegel JM (1988) Medullary regions mediating atonia. J Neurosci 8:4790-4796.

Leonard CS, Llinas R (1990) Electrophysiology of mammalian pedunculopontine and laterodorsal tegmental neurons in vitro: implications for the control of REM sleep. In: Brain cholinergic systems (Steriade M, Biesold D, eds), pp 205-223. New York: Oxford UP.

Llinas R, Terzuolo CA (1964) Mechanisms of supraspinal actions upon spinal cord activities. Reticular inhibitory mechanisms on alpha extensor motoneurons. J Neurophysiol 27:579-591.

Llinas R, Terzuolo CA (1965) Mechanisms of supraspinal actions upon spinal cord activities. Reticular inhibitory mechanisms on alpha flexor motoneurons. J Neurophysiol 28:413-422.

Lydic R, Baghdoyan HA, Hibbard L, Bonyak EV, DeJoseph MR, Hawkins RA (1991) Regional brain glucose metabolism is altered during rapid eye movement sleep in the cat: a preliminary study. J Comp Neurol 304:517-529.

Magherini PC, Pompeiano O, Thoden U (1972) Cholinergic mechanisms related to REM sleep. I. Rhythmic activity of the vestibulooculomotor system induced by an anticholinesterase in the decerebrate cat. Arch Ital Biol 110:234-259.

Magoun HW, Rhines R (1946) An inhibitory mechanism in the bulbar reticular formation. J Neurophysiol 9:165-171.

McCarley RW, Hobson JA (1975) Discharge patterns of cat pontine brain stem neurons during desynchronized sleep. J Neurophysiol 38: 751-766.

McGinty DJ, Harper RM (1976) Dorsal raphe neurons: depression of firing during sleep in cats. Brain Res 101:569-575.

Menétrey D, Gannon A, Levine JD, Basbaum AI (1989) Expression of $c$-fos protein in interneurons and projections neurons of the rat spinal cord in response to noxious somatic, articular, and visceral stimulation. J Comp Neurol 285:177-195.

Merchant-Nancy $\mathbf{H}$, Vázquez J, Aguilar-Roblero R, Drucker-Colin R (1992) C-fos proto-oncogene changes in relation to REM sleep duration. Brain Res 579:342-346.

Mitani A, Ito K, Hallanger AE, Wainer BH, Kataoka K, McCarley RW (1988) Cholinergic projections from the laterodorsal and pedunculopontine tegmental nuclei to the pontine gigantocellular tegmental field in the cat. Brain Res 451:397-402.

Morales FR, Schadt J, Chase MH (1981) Intracellular recording from spinal cord motoneurons in the chronic cat. Physiol Behav 27:355362.

Morales FR, Engelhardt JK, Soja PJ, Pereda AE, Chase MH (1987) Motoneurons properties during motor inhibition produced by microinjection of carbachol into the pontine reticular formation of the decerebrate cat. J Neurophysiol 57:1118-1129.

Morgan JI, Curran T (1991) Stimulus-transcription coupling in the nervous system: involvement of the inducible proto-oncogenes fos and jun. Annu Rev Neurosci 14:421-451. 
Mori S (1987) Integration of posture and locomotion in acute decerebrate and in awake, freely moving cats. Prog Ncurobiol 28:161-195.

Ohta Y, Mori S, Kimura H (1988) Neuronal structures of brain stem participating in postural suppression in cats. Neurosci Res 5:181202.

Owman C (1986) Neurogenic control of the vascular system: focus on cerebral circulation. In: Handbook of physiology: the nervous system, Sec 1, Vol 4 (Mountcastle VB, ed), pp 525-580. Bethesda, MD: American Physiological Society.

Pompeiano O, Hoshino K (1976) Central control of posture: reciprocal discharge by two pontine neuronal groups leading to suppression of decerebrate rigidity. Brain Res 116:131-138.

Romagnano MA, Harshbarger RJ, Hamill RW (1991) Brainstem enkephalinergic projections to spinal autonomic nuclei. J Neurosci 11: 3539-3555.

Sagar SM, Sharp FR, Curran T (1988) Expression of c-fos protein in brain: metabolic mapping at the cellular level. Science 240:13281331.

Sakai K (1988) Executive mechanisms of paradoxical sleep. Arch Ital Biol 126:239-257.

Sakai K, Sastre JP, Salvert D, Touret M, Tohyama M, Jouvet M (1979) Tegmentoreticular projections with special reference to the muscular atonia during paradoxical sleep in the cat: an HRP study. Brain Res 176:233-254.

Sakai K, Sastre JP, Kanamori N, Jouvet M (1981) State-specific neurons in the ponto-medullary reticular formation with special reference to the postural atonia during paradoxical sleep in the cat. In: Brain mechanisms and perceptual awareness (Pompeiano O, Ajmone Marsan C, eds), pp 405-429. New York: Raven.

Sastre JP, Sakai K, Jouvet M (1981) Are the gigantocellular tegmental field neurons responsible for paradoxical sleep? Brain Res 229:147161.

Sharp FR, Gonzalez MF, Sharp JW, Sagar SM (1989) C-fos expression and $\left({ }^{14} \mathrm{C}\right)$ 2-deoxyglucose uptake in the caudal cerebellum of the rat during motor-sensory cortex stimulation. J Comp Neurol 284:621636.

Sheu Y, Nelson JP, Bloom FE (1974) Discharge patterns of cat raphe neurons during sleep and waking. Brain Res 73:263-276.

Shiromani PJ, McGinty DJ (1986) Pontine neuronal response to local cholinergic infusion: relation to REM sleep. Brain Res 386:20-31.

Shiromani PJ, Lai YY, Siegel JM (1990) Descending projections from the dorsolateral pontine tegmentum to the paramedian reticular nucleus of the caudal medulla in the cat. Brain Res 517:224-228.

Shiromani PJ, Kilduff TS, Bloom FE, McCarley RW (1992) Cholinergically induced REM sleep triggers Fos-like immunoreactivity in dorsolateral pontine regions associated with REM sleep. Brain Res 580:351-357.

Siegel JM (1989) Brainstem mechanisms generating REM sleep. In:
Principles and practice of sleep medicine (Kryger MH, Roth T, Dement WC, eds), pp 104-120. Philadelphia: Saunders.

Siegel JM, McGinty DJ (1977) Pontine reticular formation neurons: relationship of discharge to motor activity. Science 196:678-680.

Siegel JM, Wheeler RL, McGinty DJ (1979) Activity of medullary reticular formation ncurons in the unrestrained cat during waking and sleep. Brain Res 179:49-60.

Soja PJ (1991) Excitability of facial motoneurons is reduced during the atonia of active sleep. Soc Ncurosci Abstr 17:644.

Soja PJ, López-Rodriguez. F, Morales FR, Chase MH (1991) The postsynaptic inhibitory control of lumbar motoneurons during the atonia of active sleep: effect of strychnine on motoneuron properties. J Neurosci 11:2804-2811.

Steriade M, McCarley RW (1990) Brainstem control of wakefulness and sleep. New York: Plenum.

Taber E (1961) The cytoarchitecture of the brain stem of the cat. I. Brain stem nuclei of the cat. J Comp Neurol 116:27-69.

Takakusaki K, Ohta Y, Mori S (1989) Single medullary reticulospinal neurons exert postsynaptic inhibitory effects via inhibitory interneurons upon alpha-motoneurons innervating cat hindlimb muscles. Exp Brain Res 74:11-23.

Valverde F (1961) Reticular formation of the pons and medulla oblongata. A Golgi study. J Comp Neurol 116:71-99.

Vanni-Mercier G, Sakai K, Lin JS, Jouvet M (1989) Mapping of cholinoceptive brainstem structures responsible for the generation of paradoxical sleep in the cat. Arch Ital Biol 127:133-164.

Vertes RP (1979) Brain stem gigantocellular neurons: patterns of activity during behavior and sleep in the freely moving rat. J Neurophysiol 42:214-228.

Vertes RP (1984) Brainstem control of the events of REM sleep. Prog Neurobiol 22:241-288.

Wang RY, Gallager DW, Aghajanian GK (1976) Stimulation of pontine reticular formation suppresses firing of serotonergic neurones in the dorsal raphe. Nature 264:365-368.

Webster HH, Jones BE (1988) Neurotoxic lesions of the dorsolateral pontomesencephalic tegmentum-cholinergic cell area in the cat. II. Effects upon sleep-waking states. Brain Res 458:285-302.

Yamamoto K, Mamelak AN, Quattrochi JJ, Hobson JA (1990a) A cholinoceptive desynchronized sleep induction zone in the anterodorsal pontine tegmentum: locus of the sensitive region. Neuroscience 39:279-293.

Yamamoto K, Mamelak AN, Quattrochi JJ, Hobson JA (1990b) A cholinoceptive desynchronized sleep induction zone in the anterodorsal pontine tcgmentum: spontaneous and drug-induced neuronal activity. Neuroscience 39:295-304.

Yamuy J, Mancillas JR, Morales FR, Chase MH (1991) C-fos-like expression in the brainstem of the cat during carbachol-induced atonia. Soc Neurosci Abstr 17:468. 